\title{
Brief Review on Metabolic Bone Disease
}

\author{
Dina el Demellawy, Jorge Davila, Ashley Shaw, Youssef Nasr
}

\begin{abstract}
Metabolic bone disease (MBD) is a broad term that describes a clinically heterogeneous group of diseases that are only united by a common denominator of an aberrant bone chemical milieu leading to a defective skeleton and bone abnormalities. From a forensic pathologist's perspective, MBDs create a challenging diagnostic dilemma in differentiating them from child abuse, particularly when the victim is an infant. Through this brief narrative review on MBD, bone pathophysiology and two relatively challenging pediatric MBDs will be discussed. Acad Forensic Pathol. 2018 8(3): 611-640
\end{abstract}

\section{AUTHORS}

Dina el Demellawy MD PhD FRCPC, Children's Hospital of Eastern Ontario - Anatomical Pathology

Roles: Project conception and/or design, data acquisition, analysis and/or interpretation, manuscript creation and/or revision, approved final version for publication, accountable for all aspects of the work, principal investigator of the current study, general supervision, general administrative support, writing assistance and/or technical editing.

Jorge Davila MD, Children's Hospital of Eastern Ontario - Diagnostic Imaging

Roles: Data acquisition, analysis and/or interpretation, manuscript creation and/or revision, approved final version for publication, accountable for all aspects of the work, writing assistance and/or technical editing.

Ashley Shaw MPH, Children's Hospital of Eastern Ontario Research Institute - Pathology

Roles: Data acquisition, analysis and/or interpretation, manuscript creation and/or revision, approved final version for publication, accountable for all aspects of the work, general administrative support, writing assistance and/or technical editing.

Youssef Nasr, University of Ottawa - Biomedical Sciences Program in Faculty of Sciences

Roles: Project conception and/or design, manuscript creation and/or revision, approved final version for publication, accountable for all aspects of the work, writing assistance and/or technical editing.

\section{CORRESPONDENCE}

Dina el Demellawy MD PhD FRCPC, 401 Smyth Rd, Pathology Department, Ottawa ON K1H 8L1, deldemellawy@cheo.on.ca

ETHICAL APPROVAL

As per Journal Policies, ethical approval was not required for this manuscript

STATEMENT OF HUMAN AND ANIMAL RIGHTS

This article does not contain any studies conducted with animals or on living human subjects

STATEMENT OF INFORMED CONSENT

No identifiable personal data were presented in this manuscript

DISCLOSURES \& DECLARATION OF CONFLICTS OF INTEREST

The authors, reviewers, editors, and publication staff do not report any relevant conflicts of interest

FINANCIAL DISCLOSURE

The authors have indicated that they do not have financial relationships to disclose that are relevant to this manuscript

KEYWORDS

Forensic pathology, Rickets, Metabolic bone disease, Osteogenesis imperfecta, Bone, Fracture

INFORMATION

ACADEMIC FORENSIC PATHOLOGY: THE OFFICIAL PUBLICATION OF THE NATIONAL ASSOCIATION OF MEDICAL EXAMINERS

@2018 Academic Forensic Pathology International • (ISSN: 1925-3621) • https://doi.org/10.1177/1925362118797737

Submitted for consideration on 4 May 2018. Accepted for publication on 21 Jul 2018 


\section{INTRODUCTION}

Metabolic bone disease (MBD) is an umbrella term that encompasses a broad spectrum of clinically different diseases that share the common finding of an aberrant bone chemical milieu leading to a defective skeleton and bone abnormalities. Metabolic bone diseases are usually characterized by a dramatic clinical presentation and manifestation that are commonly reversible once the underlying defect has been treated. Abnormalities of minerals include calcium, phosphorus, magnesium, or vitamin $\mathrm{D}$ developing as a result of dysfunctions of the various factors that control mineral homeostasis. The defective mineralization translates into rickets at the level of the epiphyseal growth plates and osteomalacia on the endocortical and cancellous bone surfaces (1). Moreover, osteogenesis imperfecta (OI) pathogenesis has been expanded from a simple collagen defect to abnormalities in bone cell metabolism and development with primary defects in osteoblast differentiation $(2,3)$.

Metabolic bone disease is to be differentiated from skeletal dysplasias, which are a larger group of genetic bone disorders that overlaps with MBD. In contrast to MBD, skeletal dysplasias are heritable diseases that have generalized abnormalities in cartilage and bone. The primary defects are in specific signal system or cell types that orchestrate processes of skeleton formation causing the bone disorder (4). For forensic pathologists, when dealing with infants who present with multiple unexplained fractures, a challenging diagnostic dilemma is differentiating between child abuse and MBD. This short overview will highlight basic bone physiology to establish a core understanding of bone dynamics and to set the stage for a discussion on bone pathophysiology in the setting of metabolic derangements as occurs in MBD, using two relatively challenging MBD entities as examples.

\section{DISCUSSION}

Pathophysiology of Bone Development and Metabolic Bone Disease

Bone is composed of proteins and minerals. The former mainly consists of type I collagen and the latter is made up primarily of calcium and pyrophosphate. About $5-10 \%$ of the bone skeleton is replaced every year in adulthood and about $85 \%$ of the body's phosphate and $99 \%$ of its calcium are contained within the skeleton as hydroxyapatite (5). The adult skeleton appears to be stable and continuously active with balanced resorption and bone formation that is tightly regulated as part of the modeling and remodeling process. This dynamic process requires serum calcium homeostasis and, thus, primary failure of organs that are crucial in calcium hemostasis, as in chronic renal failure, can lead to bone manifestations in the form of MBD.

Bone modeling is a global process characterized by non-coupled bone formation by osteoblasts or bone resorption by osteoclasts on a given surface. This occurs from birth to adulthood and results in a gain of skeletal mass and architectural changes of the immature and mature skeleton in children and adults. Modeling contributes to the periosteal expansion. Bone remodeling is a sequential coupling activity of osteoblasts and osteoclasts on a given bone surface. It occurs at discrete sites throughout the skeleton and involves repeated cycles of resorption of predominately trabecular (non-cortical) bone followed by formation leading to replacement of older bone. This occurs in the adult skeleton and is responsible for the maintenance of bone mass and the expansion of the medullary cavities of the long bones. These changes are detectable at the cellular/microscopic and macroscopic levels and involve equitable amounts of bone resorption secondary to bone formation in healthy individuals.

Bone modeling and remodeling occurs by the same cell type. Remodeling occurs at spatially discrete foci and the group of cells involved is referred to as the basic multicellular unit. The two key player cells are osteoclasts and osteoblasts. Osteoclasts arise from hematopoietic progenitors in the bone marrow and have an average lifespan of 12 days, after which they die by apoptosis (6). Osteoblasts arise from osteoprogenitor cells that are derived from primitive mesenchymal cells and have a life span that varies from a few days up to 100 days $(7,8)$. 
For routine homeostasis, the integrity of bone seems to be maintained by repopulating cells normally present in the bone microenvironment. Interestingly, bone repair and regeneration in the early post-bone marrow transplantation period suggests that hematopoietic cells and osteoblasts are derived from a common marrow progenitor (9).

Osteocytes are the resident cells of bone and are entombed whilst bone is being made. They are connected to each other and to the lining cells on the surface by cell processes within canaliculi (10). Osteocyte deficiency might contribute to bone fragility by promoting the accumulation of fatigue microdamage (10). There is a decline in osteocytes occupying lacunae from about $95 \%$ at age ten to about $70 \%$ at age 40 , remaining steady afterwards (11). Osteocyte function is not restricted to bone and these naively senile-appearing cells are actually key players in mineral homeostasis. Osteocytes arise from osteoblasts but the exact mechanism of this transformation/differentiation is unknown. However, it is suggested that when an osteoblast is committed to become an osteocyte, it reduces its rate of matrix synthesis so that the adjacent osteoblasts travel further from the cement line, eventually burying the committed preosteocyte (12).

For simplicity, bone remodeling is divided into three phases: resorption, reversal, and resting. In the resorption phase, the key player cells are osteoclasts, while in bone formation (reversal phase) osteoblasts are the stars of the show. This precisely orchestrated coupling process involves complicated pathways and is not fully understood. Regulation of osteoclast precursor commitment and osteoclastic activity is indirectly regulated by the osteoblast lineage cells through the expression of the receptor activator of NF- $x \mathrm{~B}$ ligand (RANKL) and osteoprotegerin $(13,14)$. RANKL is a product of osteoblasts and controls the function of osteoclasts. A second protein, osteoprotegerin, is also produced by osteoblasts and is a soluble inhibitor of RANKL that acts as a "brake" on osteoclast activity (15-17).

The resting phase is a quiescent period in which osteoclasts and osteoblasts rest before the cycle of remodel- ing is repeated. It is only when there is an imbalance in the coupling process that MBD such as hyperparathyroidism and Paget's disease can ensue (5). There is exciting evidence accumulating that diseases such as OI are actually a primary defect in osteoblast differentiation with collagen defects that result in changes in bone cell metabolism and development $(2,3)$. On the other hand, failure to mineralize the laid down osteoid leads to rickets and osteomalacia in immature and mature skeletons, respectively.

\section{Role of the Pathologist in Metabolic Bone Disease}

Endocrinologists and, less often, orthopedic surgeons are the main physicians that manage and diagnose MBD. Since the indication for neoplastic bone biopsy is limited in clinical practice, pathologists are uncommonly engaged in the workup of patients. Examples of pathologist engagement include when a bone biopsy (usually transiliac crest bone) is required, when bone parts are excised during stabilization of a fragility fracture, or when studies and tissue retrieval are needed during postmortem examination (18). Some MBDs can be diagnosed using decalcified sections of bone, this is particularly true of Paget disease and to a lesser extent osteoporosis (19). When MBD is suspected, the bone needs to be fixed in absolute alcohol, not formalin, to prevent it from being dissolved (5). The specimen is processed without being decalcified and then embedded in methyl methacrylate plastic and sectioned with a special microtone for microscopic examination. Non-decalcified sections can be stained using toluidine blue or the Masson Goldner technique to separate osteoid from mineralized bone (5). The most important stain is Goldner's trichrome, which differentially stains mineralized bone (green) and unmineralized osteoid (red). The histology of bone structure, formation, and resorption can be quantitatively assessed using bone histomorphometry.

Histomorphometry allows for the two-dimensional measurement of the three-dimensional structure of bone (20). Variables are derived from primary measurements made at the microscope, such as area, perimeter, and thickness. Histomorphometric parameters are generally divided into structural and remodeling, 
with the latter including static and dynamic parameters. Nomenclature, mathematical derivations, and units have been standardized by the American Society of Bone and Mineral Research (21). Thus, trabecular bone volume can be measured as a percentage of the total biopsy and the surface osteoid can be measured as osteoid volume or osteoid surface area. The dynamic parameter requires the pre-biopsy use of tetracycline. Tetracycline is characterized by its fluorescence, binding irreversibly to hydroxyapatite and being trapped at the mineralization front and can measure the mineralization lag and mineral apposition rate $(22,23)$. Semiautomated and automated image analysis coupled to sophisticated stereology software have largely substituted the manual techniques and can produce most of these figures automatically $(5,24)$.

\section{Bone Embryology and Development}

Most of the craniofacial skeleton originates primarily from neural crest cells (ectoderm), which emigrate from the neural tube, while the rest of the skeleton results exclusively from mesodermal contributions (2527). These mesenchymal condensations will evolve differently depending on the type of ossification they will undergo, endochondral or intramembranous (28). The first extracellular molecules shown to be implicated in skeleton formation were the two major collagens, type I collagen in bone and type II collagen in cartilage (5).

\section{Rickets}

Generally, rickets is a result of a disturbance of endochondral bone ossification occurring at the epiphyseal growth plate through defective mineralization of osteoid tissue which in turn leads to excessive accumulation of osteoid tissue with deformities (bowing and short stature) throughout the immature skeleton (29). See Images 1 to 3 for radiological images of rickets deformities and Images $\mathbf{4}$ and $\mathbf{5}$ for images of rickets after treatment.

These changes occur due to remodeling of cancellous bone, which allows expansion of the marrow cavity, and apposition of periosteal bone, which affects bone width and cortical thickness. Rickets occurs during growth in children and has different etiological subtypes (Table 1). The two main subtypes of rickets are calcipenic and phosphopenic. Both forms show failure of mineralization but in the calcipenic form, hypocalcemia is characteristic and results in a secondary hyperparathyroidism that leads to increased bone resorption and osteopenia. On the contrary, osteopenia does not occur in the phosphopenic forms as they are characterized by normocalcemia. Phosphopenic forms of rickets may be hereditary or acquired (Table 1). Hypophosphatemia is a common denominator of both groups of rickets (31). It prevents apoptosis in the hypertrophic cells in the growth plate. In the absence of apoptosis, the hypertrophic cells accumulate in the growth plate and form the rachitic bone (32). In calcipenic rickets, phosphaturia leading to hypophosphatemia occurs due to secondary hyperparathyroidism. In phosphopenic rickets (hypophosphatemic rickets), phosphate deficiency is the primary defect that results most commonly from increased renal excretion of phosphate. It is associated with normal or slightly elevated serum parathyroid hormone (PTH). Calcium, vitamin D, parathyroid hormone, and phosphorus interact in such a way that deficiencies of one are often associated with disorders of the others (33). Healing infantile rickets has a very different radiological presentation than classic rickets, and an early sign of healing is calcification of the zone of provisional calcification, resulting in sclerosis of the metaphysis. With treatment, these radiological features reverse over the course of a few months (34). There are also subtle histological signs of healing rickets that must be interpreted within the right clinical and radiological context.

In both forms of rickets, the trabecular bone volume is normal but there is a marked increase in the osteoid volume and the osteoid surface area. The available ambient calcium (or occasionally phosphorus) is not sufficient to form calcium hydroxyapitate crystals, which are necessary to mineralize bones. The degree of bone mineralization cannot be appreciated on a standard decalcified hematoxylin and eosin (H\&E) preparation and thus undecalcified bone histomorphometry is necessary to evaluate how much of the bone is mineralized in cases of rickets. 
The diagnostic feature of rickets is wide osteoid seams. With normal bone turnover, there is a thin layer of unmineralized osteoid covering not more than $15 \%$ of the bone surfaces. In rickets, the bone surfaces are covered with thick seams of unmineralized osteoid that stain red using the Gomori Goldnar stain.

Histologically, rickets is characterized by an enlargement of the costochondral junction, an increased hypertrophic zone of cartilage (Images 6 and 7; see Image 8 for normal growth plate histology), and columns of hypertrophic cells that show disorderly alignment and pronounced variation in size, with large lacunae most notable at the periphery (Image 9). The normal- ly clear and distinct junction between the hypertrophic and provisional calcification zones is entirely lost. Instead, there is a disorganized cartilaginous area penetrated by blood vessels with large tongues and islands of calcified cartilage with viable chondrocytes covered with thin osteoid deep in the primary spongiosa (Images 6, 7, and 9) (35). The diaphyseal trabecular bone is thin woven bone that is poorly mineralized. Thickened osteoid seams covering more than $15 \%$ of the surface of the trabeculae are noted (Images 10 and 11). In case of rickets associated with a fracture, the trabeculae adjoining the fracture site show only slight signs of remodeling and the callus tends to show exuberant osteoid and metaplastic cartilage, with only

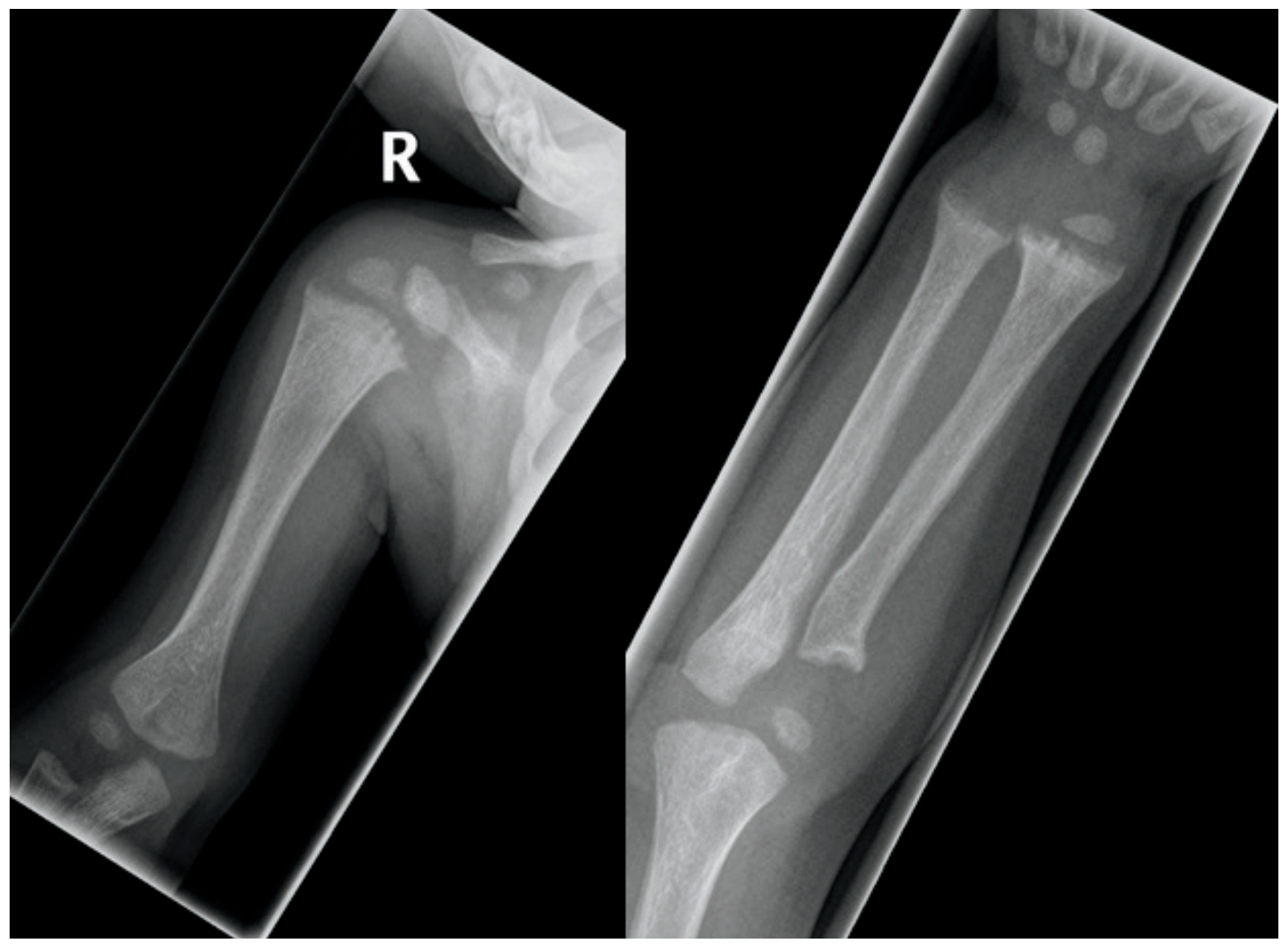

Image 1: 11/2 year old male infant with X-linked hypophosphatemic rickets. Frontal view of the right humerus shows widening and irregularity of the proximal physis (fraying). Frontal view of the right radius and ulna show fraying of the proximal and distal radial physis and widening of distal metaphyseal end of the ulna with cupping at the distal radial and ulnar metaphysis. 
minimal mineralization (Image 12; see Images 13 and 14 for examples of normal callus formation).

\section{Considerations in Rickets in Neonates and Infants}

There are considerable controversial results in published studies and reviews in identifying the etiology of classic metaphyseal lesions (CML) in neonates and

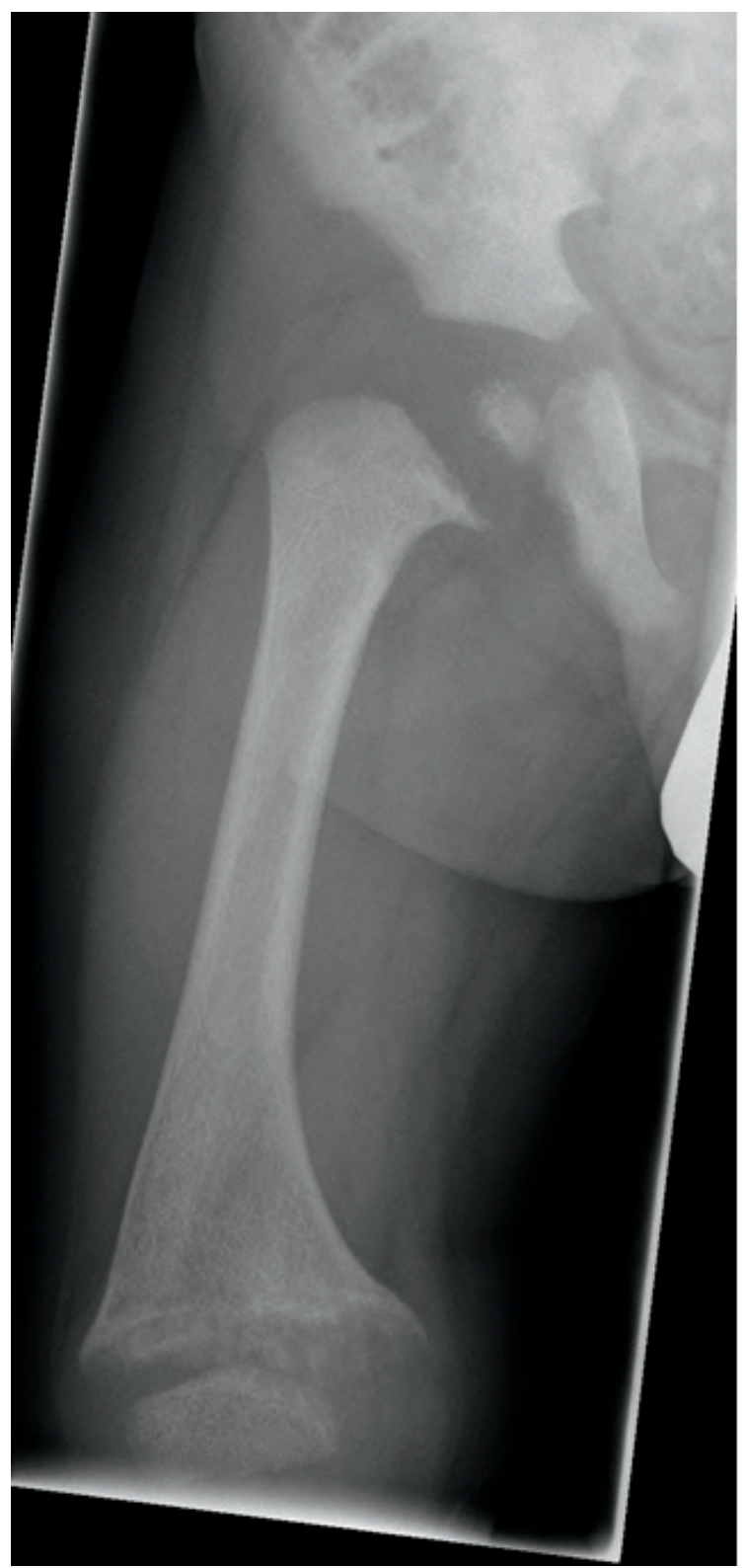

infants, as well as unexplained fractures in neonates $(34,36)$. The American Academy of Pediatrics' Committee on Child Abuse and Neglect (AAPCCAN) has issued guidelines for the evaluation of children with multiple unexplained fractures, concluding they are almost always due to abuse (37). According to Kleinman et al., CML are commonly identified in patients with a high risk for abuse and are a highly specific

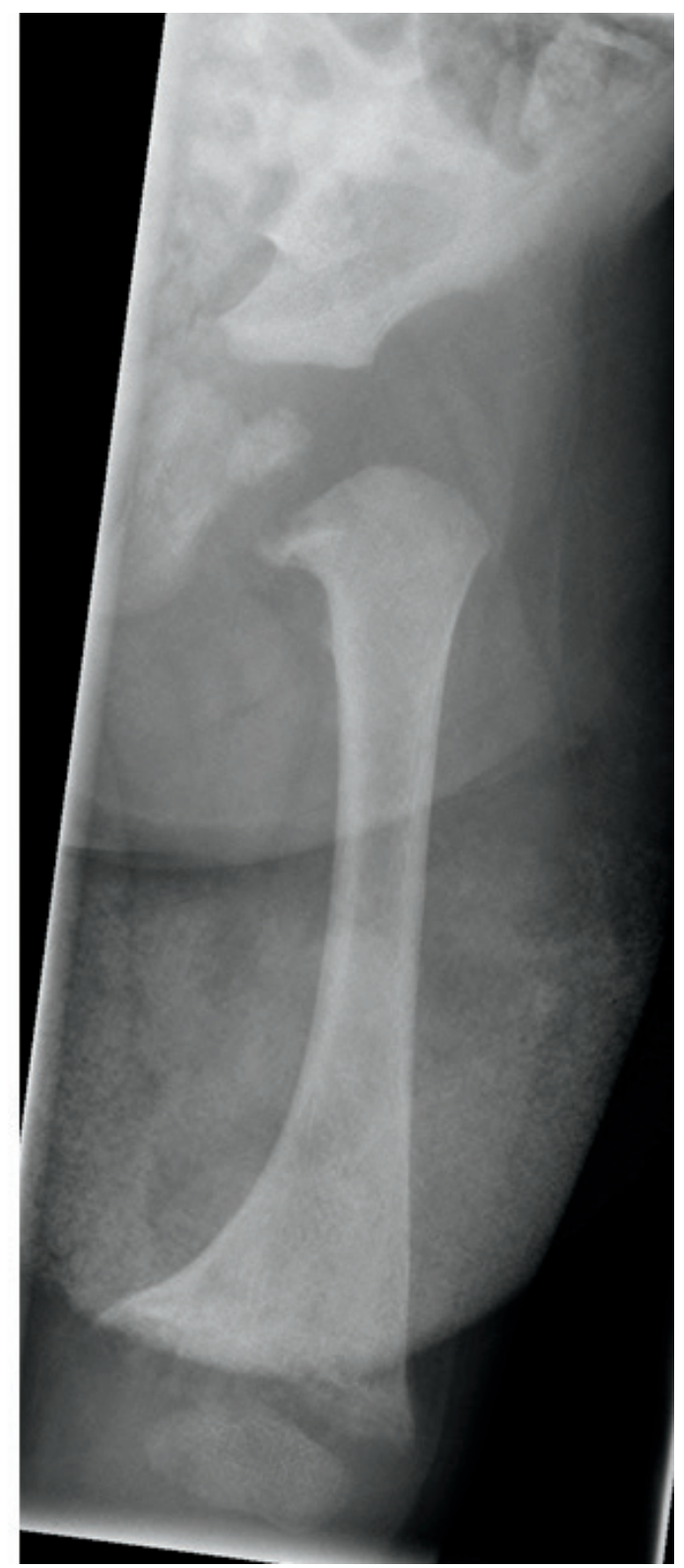

Image 2: Frontal view of the femurs shows fraying and cupping in bilateral distal metaphysis with mild lateral convexity bowing deformity of bilateral femoral physis. 
indicator of child abuse $(38,39)$. This notion has been challenged by others who attribute the phenomenon to a manifestation of MBD in infancy $(34,40-$ 42). For example, Miller and Mirkin interpreted the CMLs presented in Kleinman's articles as showing poor bone mineralization of the metaphysis, potentially attributable to MBD of infancy (42). However, in older children there is evidence that the histology of childhood rickets and child abuse-related fractures are distinct (43).

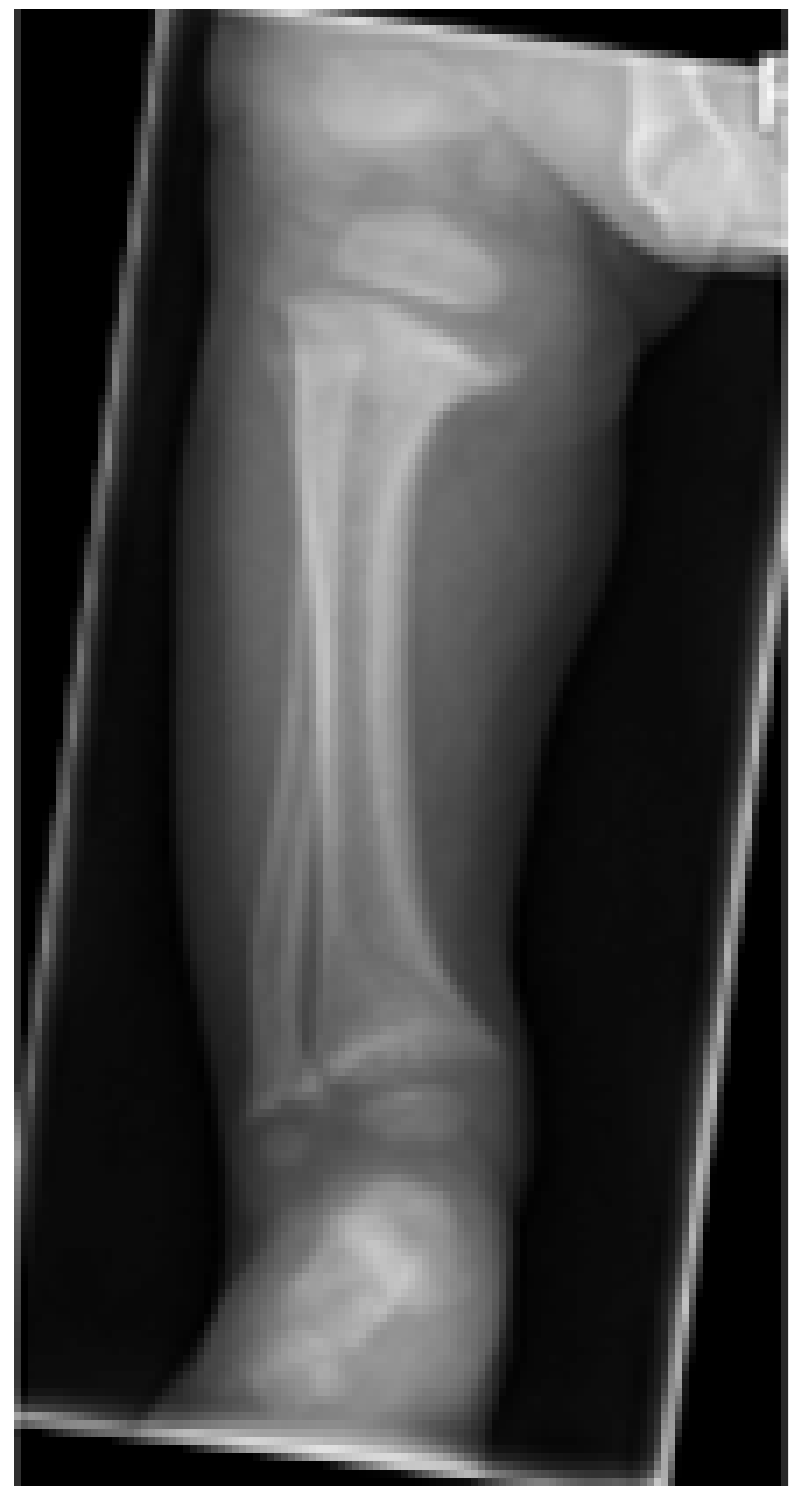

Dealing with unexplained fracture(s) in an infant is challenging, particularly as more authors acknowledge that child abuse and healing infantile rickets are readily confused. A recent study of 41 infants who died of sudden infant death syndrome found that only $7 \%$ of bone biopsies proving rickets were identified by pediatric radiologists (44). Based on autopsy studies, it is estimated that $80 \%$ of rickets is missed on radiographs. As a result, there is rising awareness that a pathologist experienced in infantile rickets needs to

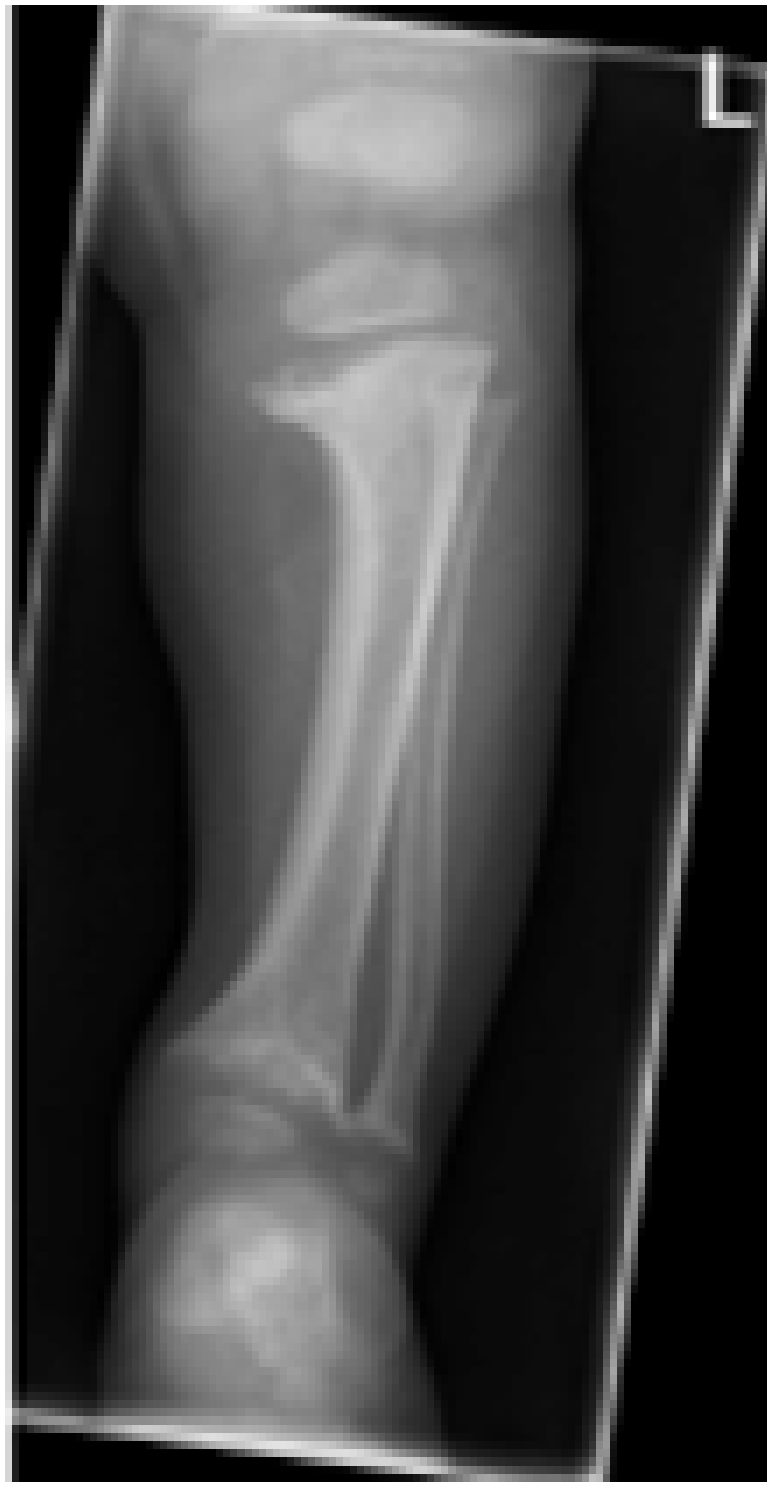

Image 3: Frontal views of bilateral tibiae and fibulae show fraying and cupping of bilateral proximal and distal tibial and ulnar metaphysis with mild lateral convexity bowing deformity of the tibial and fibular physis. 
review bone sections or biopsies prior to considering child abuse as the cause (33).

Pediatric victims with multiple rib/chest wall fractures have been shown in the trauma literature to possess associated internal injuries in $91 \%-100 \%$ of cases (45, 46). It can be inferred that the absence of swelling, bruising, functional impairment of the affected bone, and the filling-in of the CML without exuberant callus on follow-up are features supporting a diagnosis of rickets.

Metabolic bone disease in young infants with multiple unexplained fractures is multifactorial in etiology and often confused for child abuse. Neonatal rickets starts in utero and is due to multiple factors such as decreased fetal bone loading often secondary to intrauterine confinement (as in multiple birth pregnancies), maternal vitamin D deficiency during pregnancy, and inadequate maternal calcium and/or and phosphate absorption during pregnancy (34, 47-49). Maternal hypocalcemia could be related to maternal hypomagnesemia, which leads to osteopenia in the developing fetus (50-55). Pregnant women are managed with magnesium sulfate for seizures induced by preeclampsia or eclampsia for fetal neuroprotection in expected early preterm labor (less than 32 weeks) and to prolong pregnancy for a day or two in order to administer antenatal corticosteroids to enhance fetal lung maturity, as in cases of maternal diabetes melli-

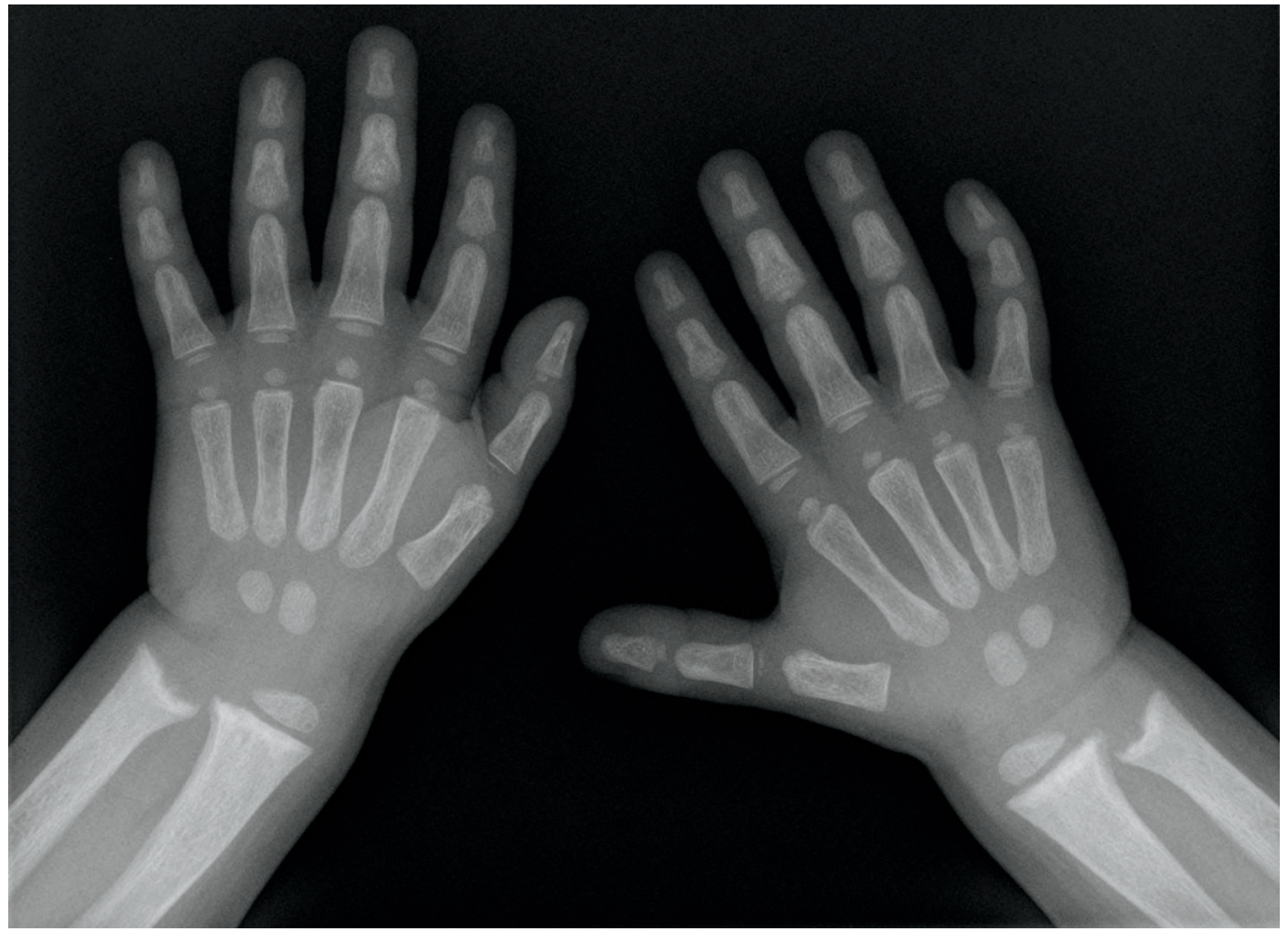

Image 4: Ten months after treatment, frontal view of the hands and wrists shows partial interval improvement of the fraying and cupping in bilateral distal radial and ulnar metaphysis. 
tus. Not all cases of infantile rickets start in utero. A subset of early infantile rickets can occur in the first few months of life after vitamin D stores gained in utero are depleted, a condition exacerbated by lack of supplementation and the demands of rapid bone growth (47).

\section{Osteogenesis Imperfecta}

Osteogenesis imperfecta is a genetically heterogeneous skeletal dysplasia with an incidence of approximately 1 in 10 000-20 000 births (56-57). The 1979 Sillence classification divided OI into four types, from mild to lethal, on the basis of clinical and radiographic features (58). See Images $\mathbf{1 5}$ to $\mathbf{1 7}$ for radiological images of OI. The underlying pathophysiological defect in OI is a disorder of type I collagen. Mutations in the COLIA1 and COLIA2 genes are responsible for more than $90 \%$ of cases (59). In 2006, identification of the first gene for recessive osteogenesis imperfecta was made (60). This led the way for discovery of further genetic mutation and a revised classification that represents a tremendous leap from the original description of osteogenesis imperfecta as an autosomal dominant disorder caused by mutations in COL1A1 and COL1A2, coding for the $\alpha 1$ and $\alpha 2$ chains of type I collagen (61). The classification now includes recessive forms caused by gene defects for protein products that interact with collagen for folding or post-translational modifications, as well as others, though rarer, that affect bone mineralization and decrease collagen production $(62,63)$. The most recently discovered gene defects drive changes in osteoblastic differentiation that result in abnormal bone cell metabolism and development $(63,64)$. Thus, it is not surprising that high bone turnover has been observed especially in the more severe types of OI (types III and IV) (65). Studies of OI in mice revealed marked osteo-
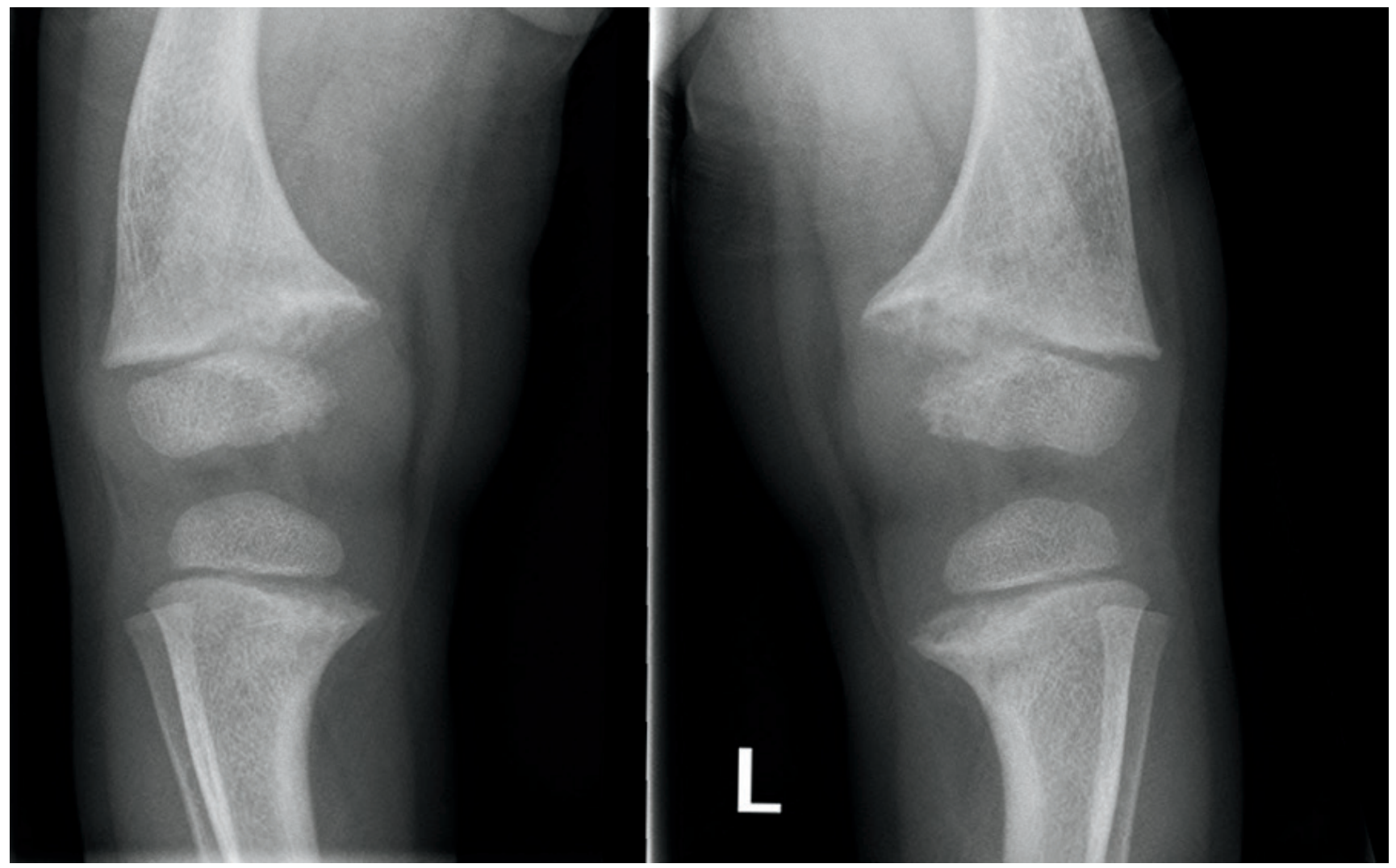

Image 5: Ten months after treatment, frontal view of the knees shows partial interval improvement of the fraying and cupping in bilateral distal femoral and proximal tibial metaphysis with lateral convexity bowing deformity of bilateral femora and tibiae. 
blastic differentiation and accumulation of immature osteoblast lineage cells that may induce changes in the bone cellular microenvironment toward enhanced osteoclast differentiation $(63,66)$.

Genetic heterogeneity of OI is further complicated by extensive phenotypic variability of each genetic locus and different modes of inheritance $(65,67)$. There is no genotype-phenotype correlation that is sufficiently accurate for predicting lethality in an individual case, and the general phenotype-genotype correlations should therefore not be the deciding factor in pregnancy terminations (68).

Despite the phenotypic overlap, the different subtypes of OI are classically the following: type I is the most common form, while type II is the most severe form. The age of presentation inversely correlates with the disease severity. Type I and type IV OI are less severe and thus show normal life expectancy in the majority of patients. Type II presents as stillbirth or neonates that die within the first month after birth in the majority of cases $(69,70)$. Respiratory impairment and neurological complications of basilar invagination contribute to early death in patients diagnosed with type III (71).

In general, patients with OI present with blue sclerae, wormian bones, dentinogenesis imperfecta, and fractures (Image 18). Other signs can be observed, such as triangular face, short stature, capsular ligamentous hyperlaxity, cardiovascular and eye abnormalities, hearing loss, platybasia, and basilar invagination (2, 69, 70). Restriction of forearm movements, progressive joint contractures, and craniosynostosis can also be observed (69). Complete or incomplete fractures of the shaft of long bones and thoracolumbar vertebral compression fractures are observed more frequently in patients with OI (72).

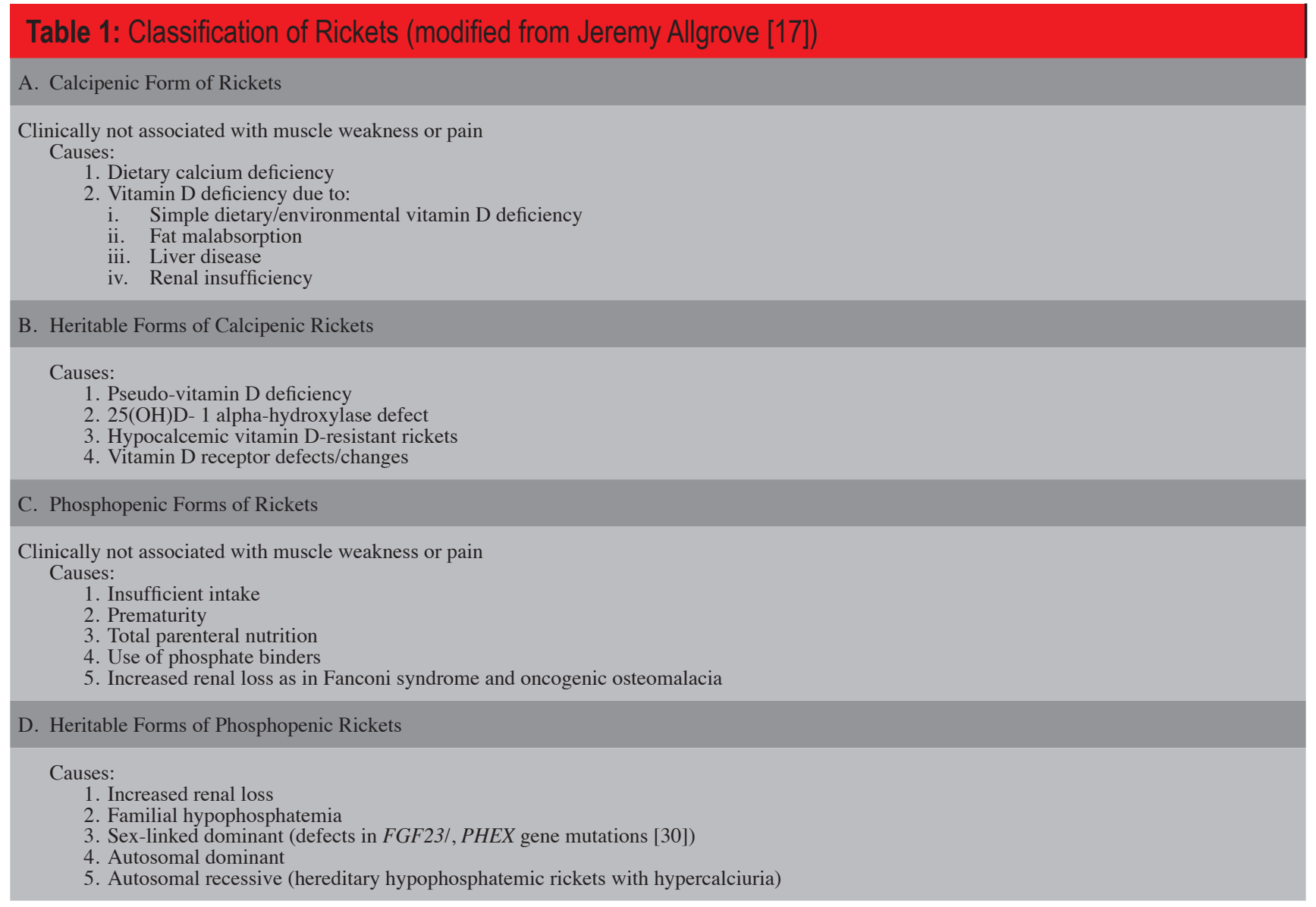

\section{Page 620}

el Demellawy et al. • Metabolic Bone Disease

ACADEMIC FORENSIC PATHOLOGY: THE OFFICIAL PUBLICATION OF THE NATIONAL ASSOCIATION OF MEDICAL EXAMINERS

C2018 Academic Forensic Pathology International

Downloaded from www.afpjournal.com by an AFP Journal subscriber

This article is for personal use only and may not be shared or distributed in any fashion 
As implied by the disease name, the histopathological hallmark is bone malformation (Image 19A). The bone trabeculae are poorly attenuated, thin, and have reduced osteoid matrix (Image 19B; see Image 20 for a comparison with normal trabeculae). The bone cortices are thin. As a result of the weak osteopenic bone, pathological fractures are common with exuberant callus formation (Images 21A and B). The growth plate, however, shows no or only minimal disorganization. A comparison of the histological features of rickets vs. OI is shown in Table 2.

Multiple and complex fractures, particularly of the skull, sternum, scapula, vertebral spinous processes, and/or posteromedial ribs at various stages of repair and healing are highly indicative of child physical abuse $(72,73)$. This leads to a great deal of suspicion and perhaps injustice to care givers of children with OI. Caregivers of individuals with OI are not uncom- monly suspected of perpetrating child abuse by health teams during the initial treatment of fractures before the diagnosis is established (74-77).

\section{CONCLUSION}

An improved understanding of the pathophysiology of bone development and the clinical, radiographic, and histologic hallmarks of metabolic bone disease can support physicians in the timely diagnosis and differentiation of MBD from childhood physical abuse. This differentiation can be particularly challenging in cases of healing infantile rickets or osteogenesis imperfecta. When possible, the analysis of bone sections or biopsies by a pathologist experienced in infantile rickets can help to identify or exclude the histological hallmarks of these MBDs and help differentiate MBD cases from child abuse (33).

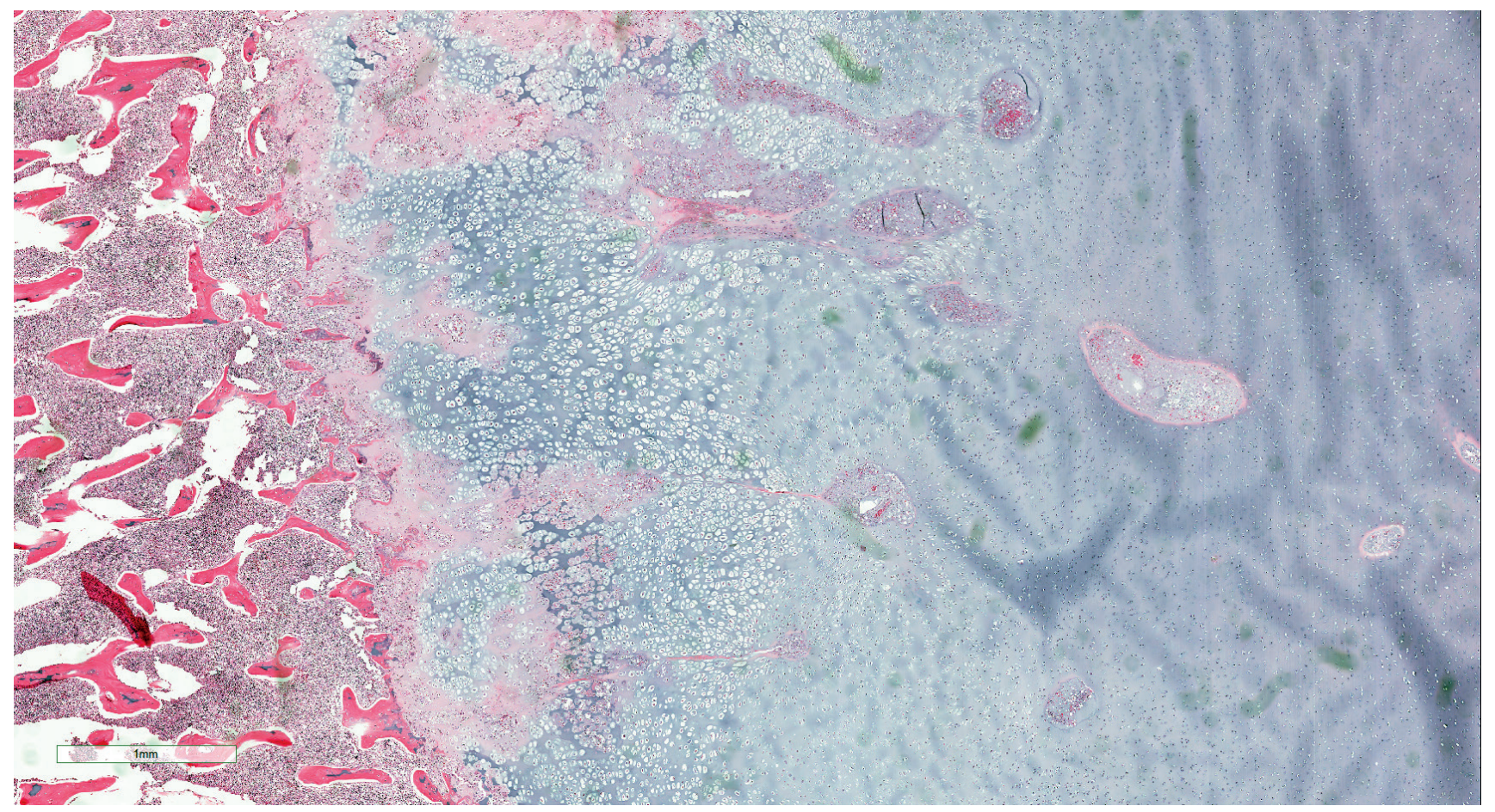

Image 6: Rickets bone changes. The epiphyseal plate is enlarged in height and width with marked and striking distortion of the hypertrophic cell zone (H\&E, x200). 


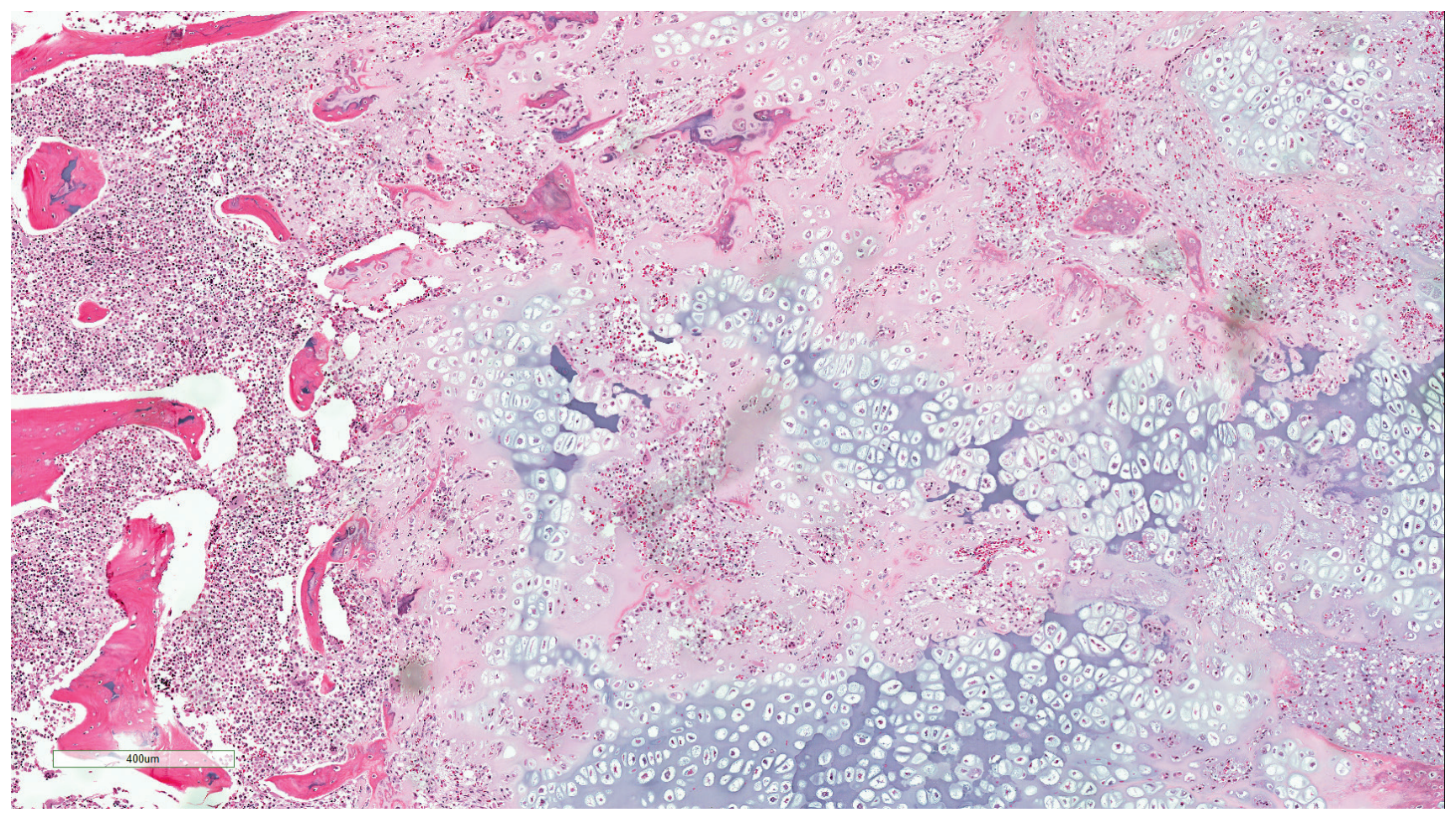

Image 7: Base of the epiphyseal plate at the junction with the primary spongiosa. There is a poorly defined zone of provisional calcification; loss of the normal orderly columns and replacement by a marked increase in the axial height of the zone of hypertrophy. Note disorderly and profligate profusion of cells with a minimal amount of intervening matrix, failure of mineralization, and presence of vascular invasion. Only a few of the defective bars between the columns of chondrocytes and virtually no deposition of mineral is noted (H\&E, $\mathrm{x200)}$. Note the tongues of viable cartilage without evidence of active enchondral ossification. 


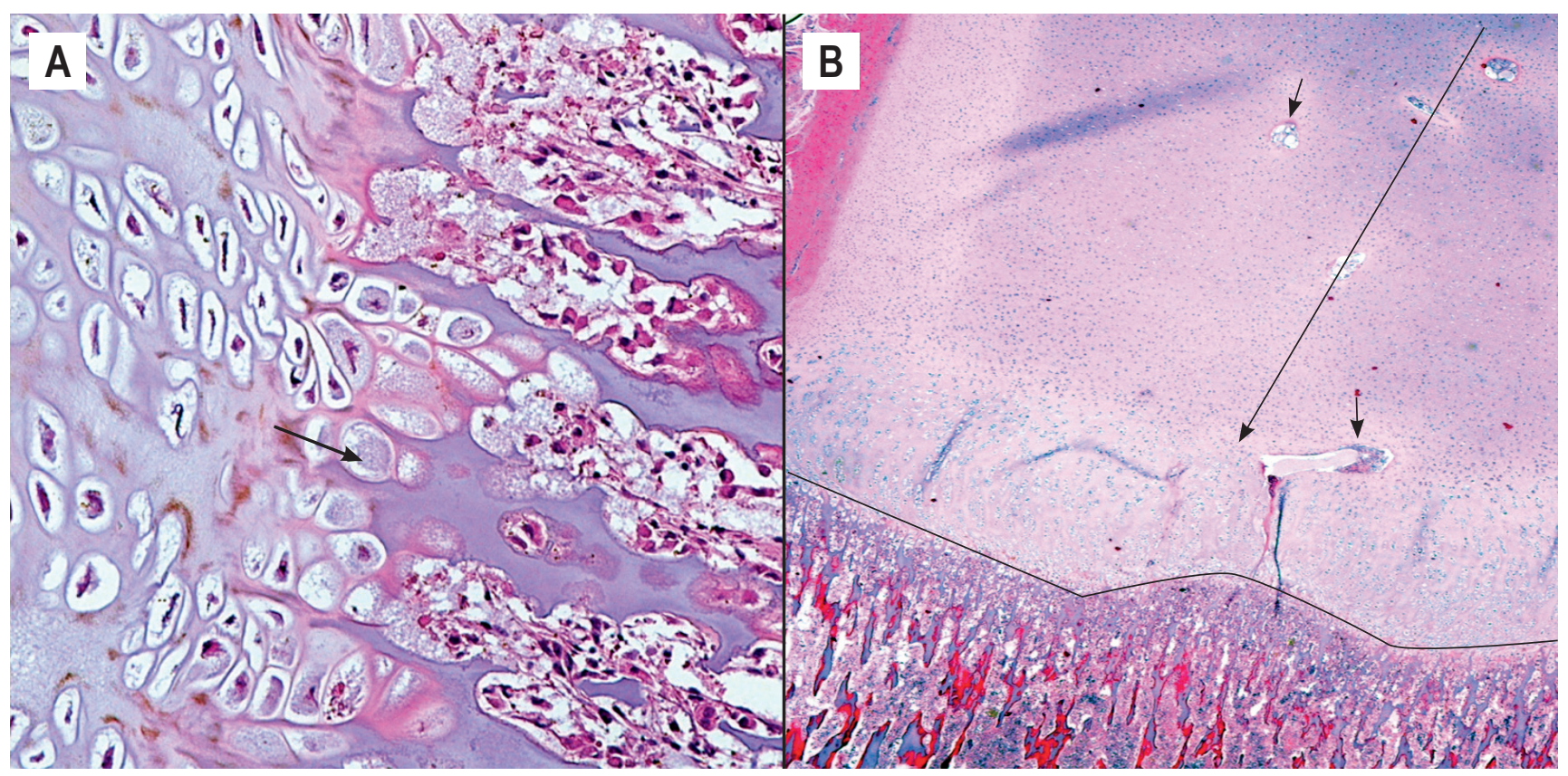

Image 8: A) Normal growth plate with hypertrophic cartilage showing degeneration at the zone of calcification (degenerated cartilage highlighted by arrow). Note preserved cartilaginous matrix which is used by osteoblasts as a template to deposit osteoid and proceed with osteochondral ossification (H\&E, x400). B) Normal growth plate in a newborn. Note the almost perfectly straight junction at the base of the growth plate and the primary spongiosa (highlighted by black line). Note ossification centers (blood vessels highlighted by short arrows) are away from the base of the growth plate. Note the distinct cartilaginous zone is formed by proliferative cartilage (highlighted by the long line), which is in contrast to rickets in which the bulk of the growth plate is formed by hypertrophic cartilage (H\&E, x40) 


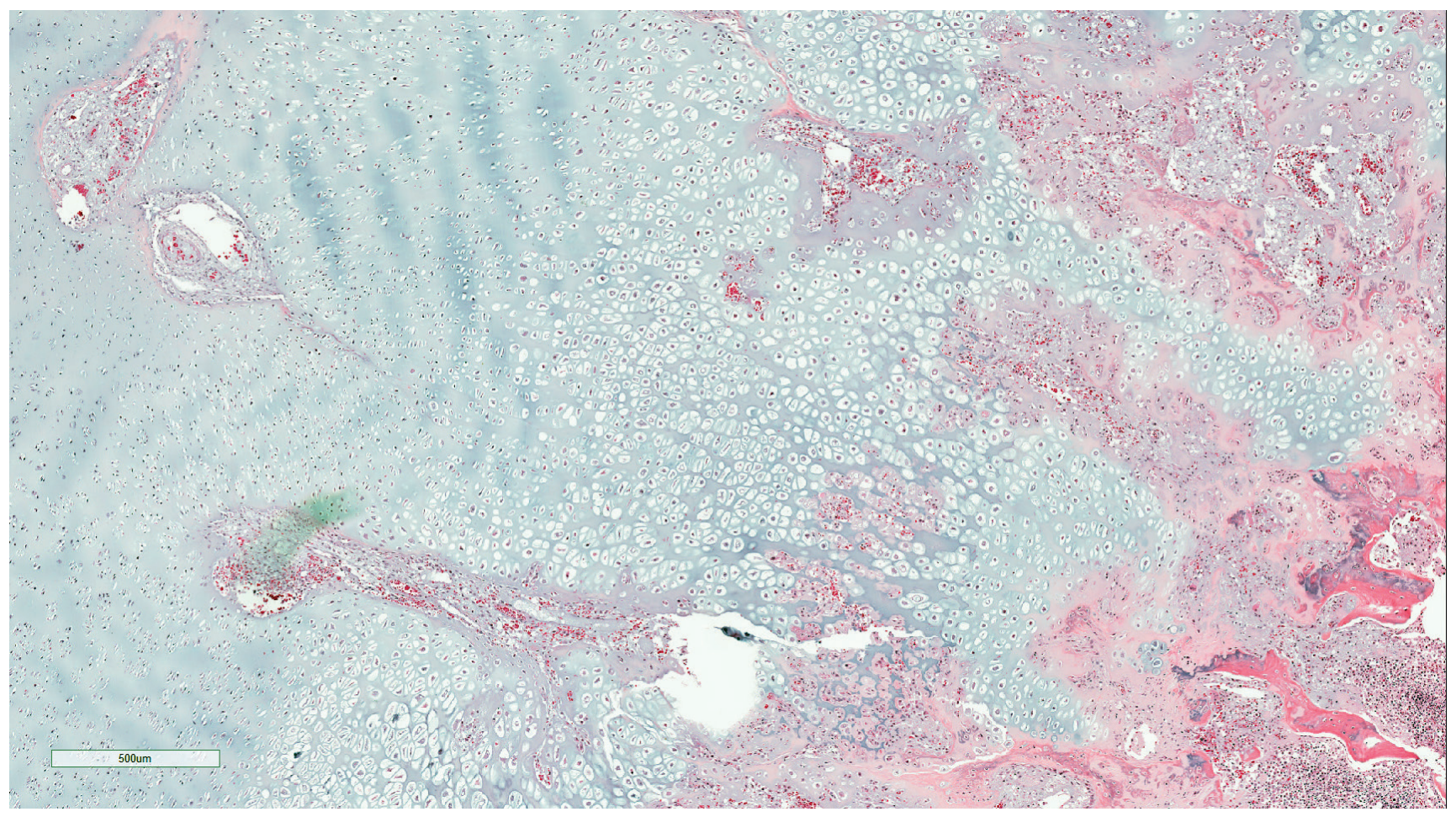

Image 9: Base of the epiphyseal plate at the junction with the primary spongiosa. There is a poorly defined zone of provisional calcification; loss of the normal orderly columns and replacement by a marked increase in the axial height of the zone of hypertrophy. Note disorderly and profligate profusion of cells with a minimal amount of intervening matrix, failure of mineralization, and presence of vascular invasion. Only a few of the defective bars between the columns of chondrocytes and virtually no deposition of mineral is noted (H\&E, $\mathrm{x} 200)$.

Page 624

el Demellawy et al. - Metabolic Bone Disease 


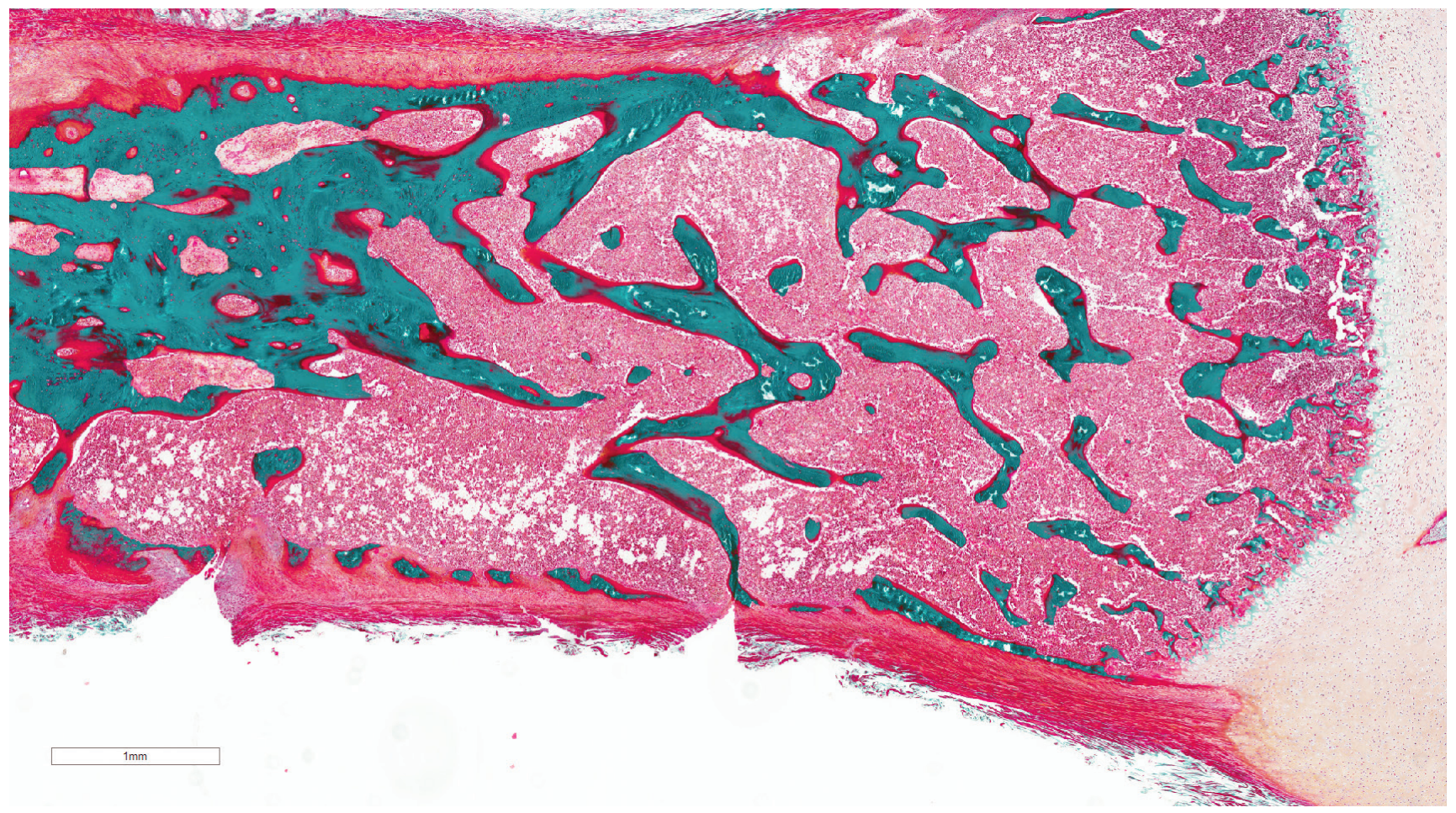

Image 10: The medullary bone shows the bony trabeculae to be thin \& irregular. There is a thick layer of unmineralized bone (osteoid seam - staining red)) surrounding the mineralized segment (staining green) (undecalcified bone Masson Goldner's trichrome, x200).

\section{Page 625}

el Demellawy et al. • Metabolic Bone Disease

ACADEMIC FORENSIC PATHOLOGY: THE OFFICIAL PUBLICATION OF THE NATIONAL ASSOCIATION OF MEDICAL EXAMINERS

C2018 Academic Forensic Pathology International

Downloaded from www.afpjournal.com by an AFP Journal subscriber

This article is for personal use only and may not be shared or distributed in any fashion 


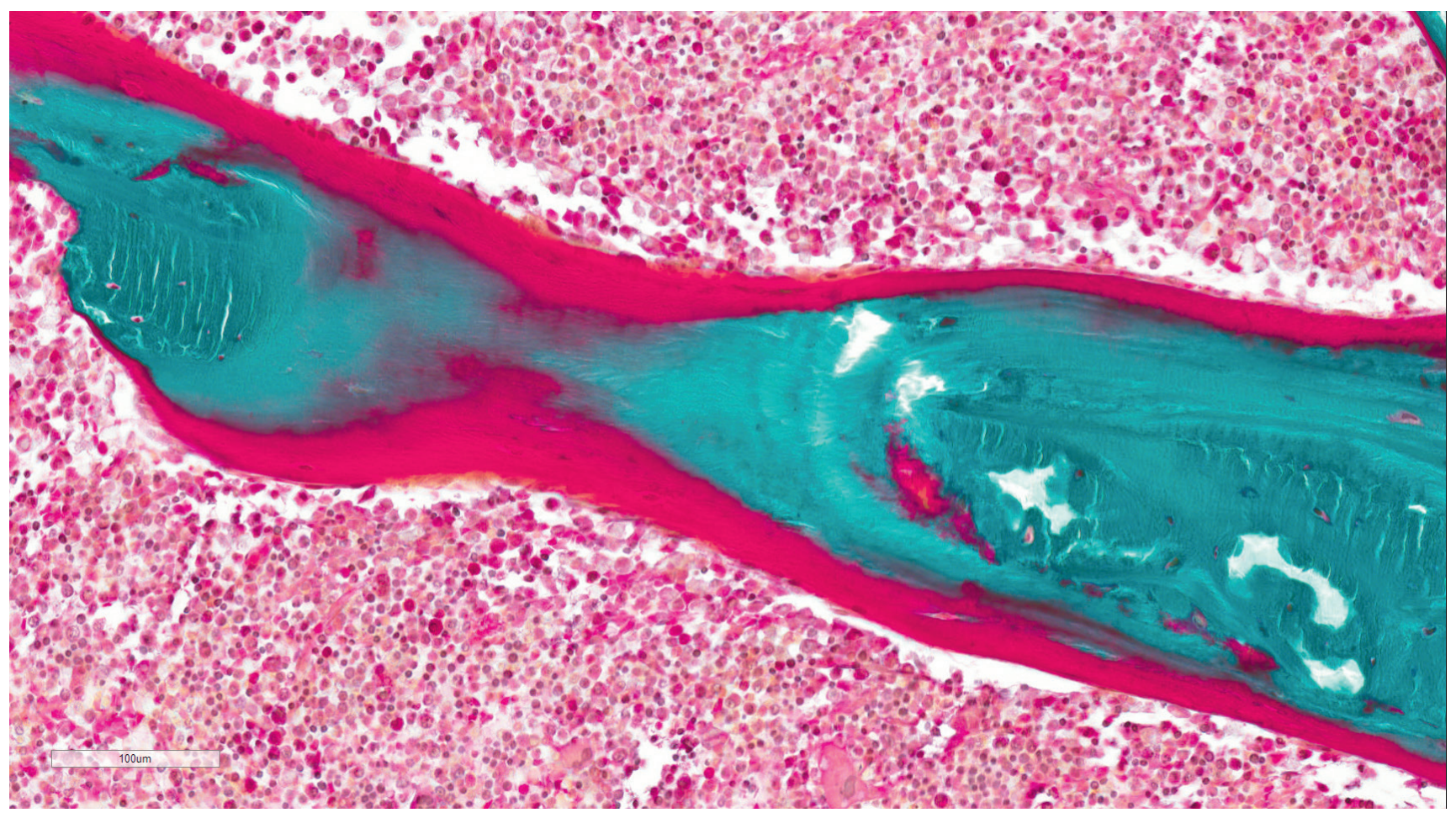

Image 11: The medullary bone shows the bony trabeculae to be thin \& irregular. There is a thick layer of unmineralized bone (osteoid seam - staining red) surrounding the mineralized segment (staining green) (undecalcified bone Masson Goldner's trichrome, x400). 


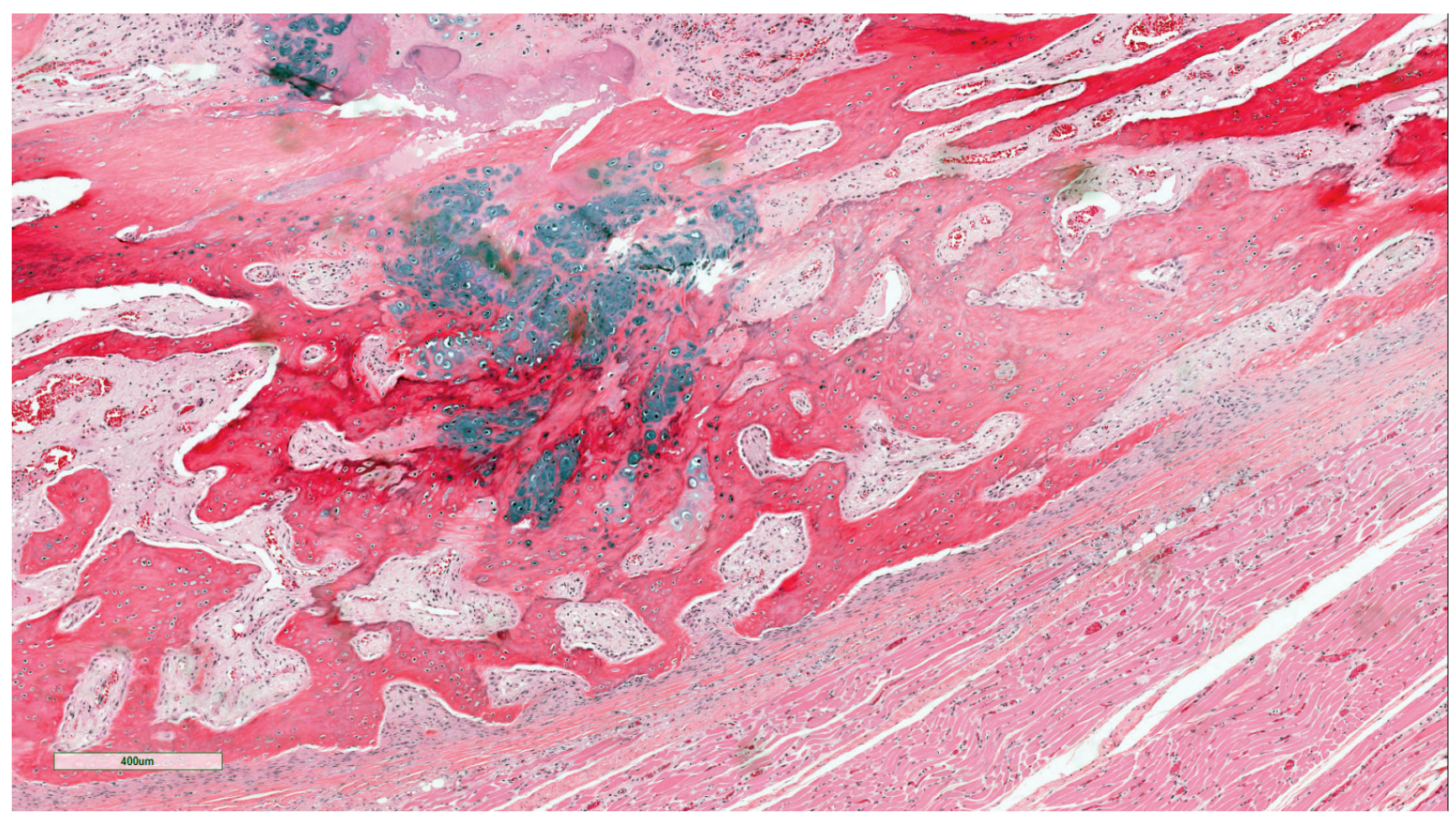

Image 12: A bony fracture with osteocartilagenous callus formation occurring in an infant with rickets. There is a central mass of hyaline cartilage within the callus and a periphery endochondral ossification, showing transition from osteoid to woven bone formation. (H\&E, $\mathrm{x} 200)$.

\section{Page 627}




\section{INVITED REVIEW}

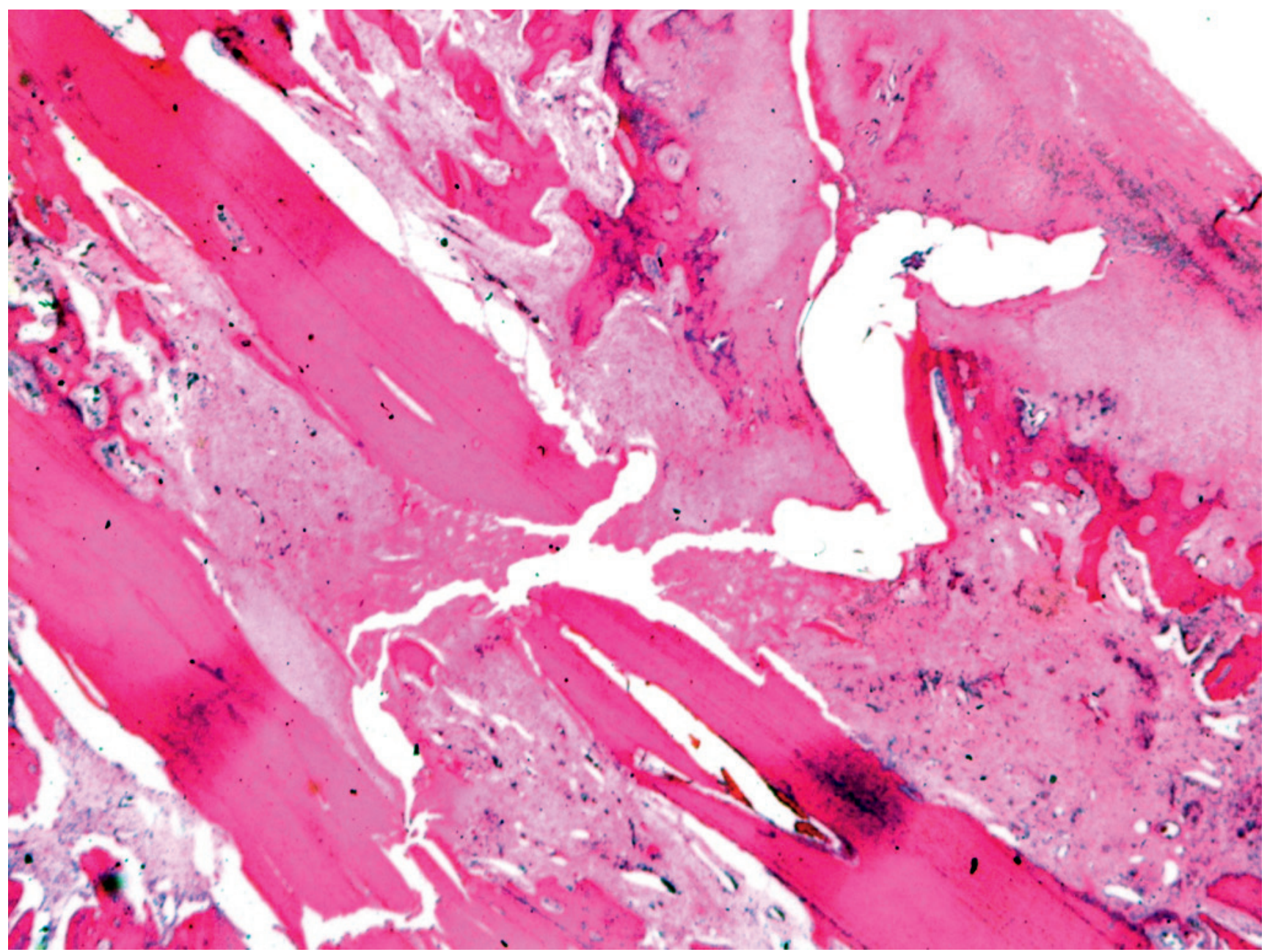

Image 13: Acute fracture callus on the tibia of a 4-year-old (H\&E, x200).

Page 628

el Demellawy et al. - Metabolic Bone Disease

ACADEMIC FORENSIC PATHOLOGY: THE OFFICIAL PUBLICATION OF THE NATIONAL ASSOCIATION OF MEDICAL EXAMINERS

C2018 Academic Forensic Pathology International

Downloaded from www.afpjournal.com by an AFP Journal subscriber

This article is for personal use only and may not be shared or distributed in any fashion 


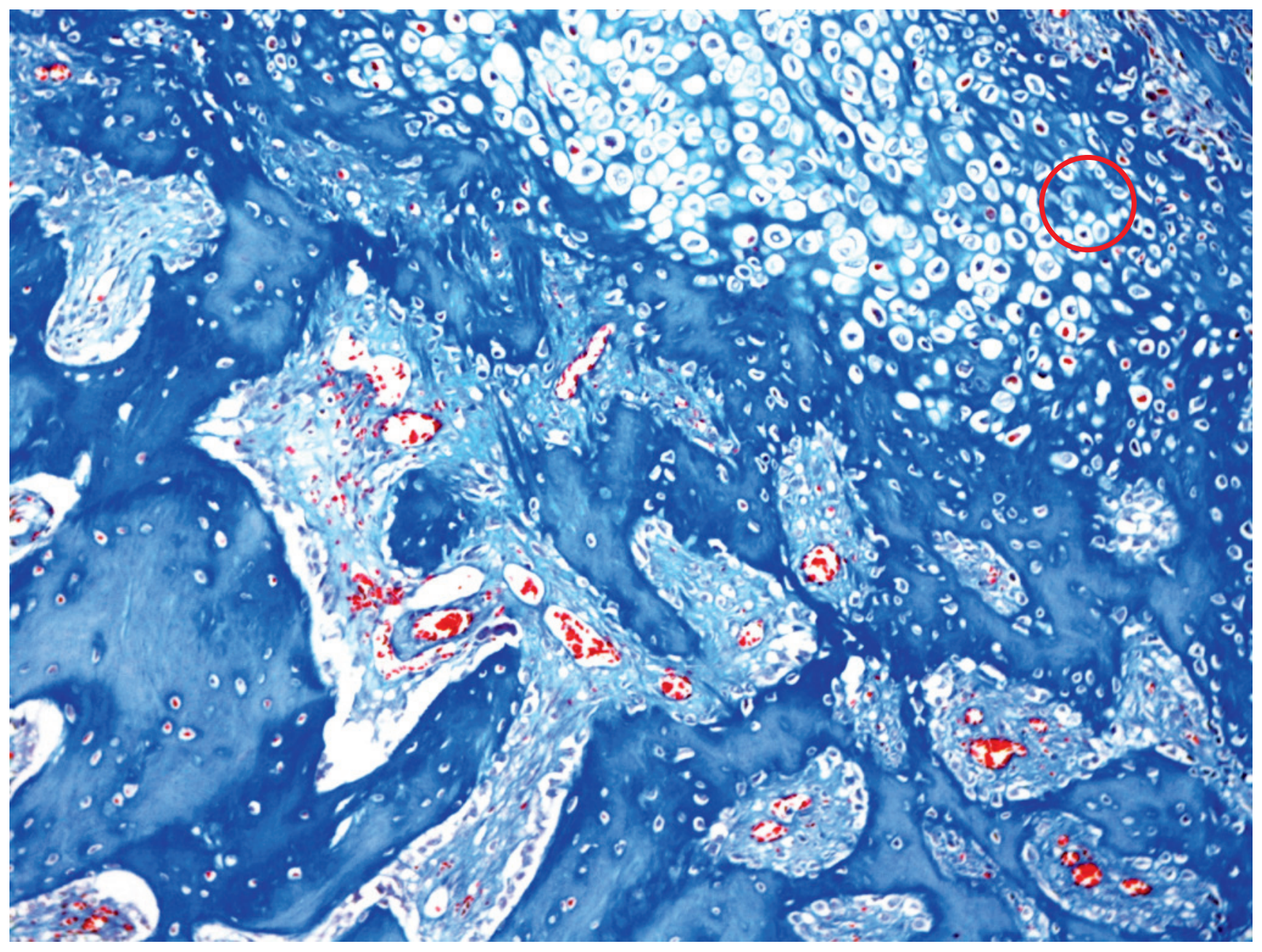

Image 14: Organizing long bone fracture with osteocartilagneous callus formation. Note circle highlighting the cartilaginous callus (Masson trichrome, $\mathrm{x} 400)$. 

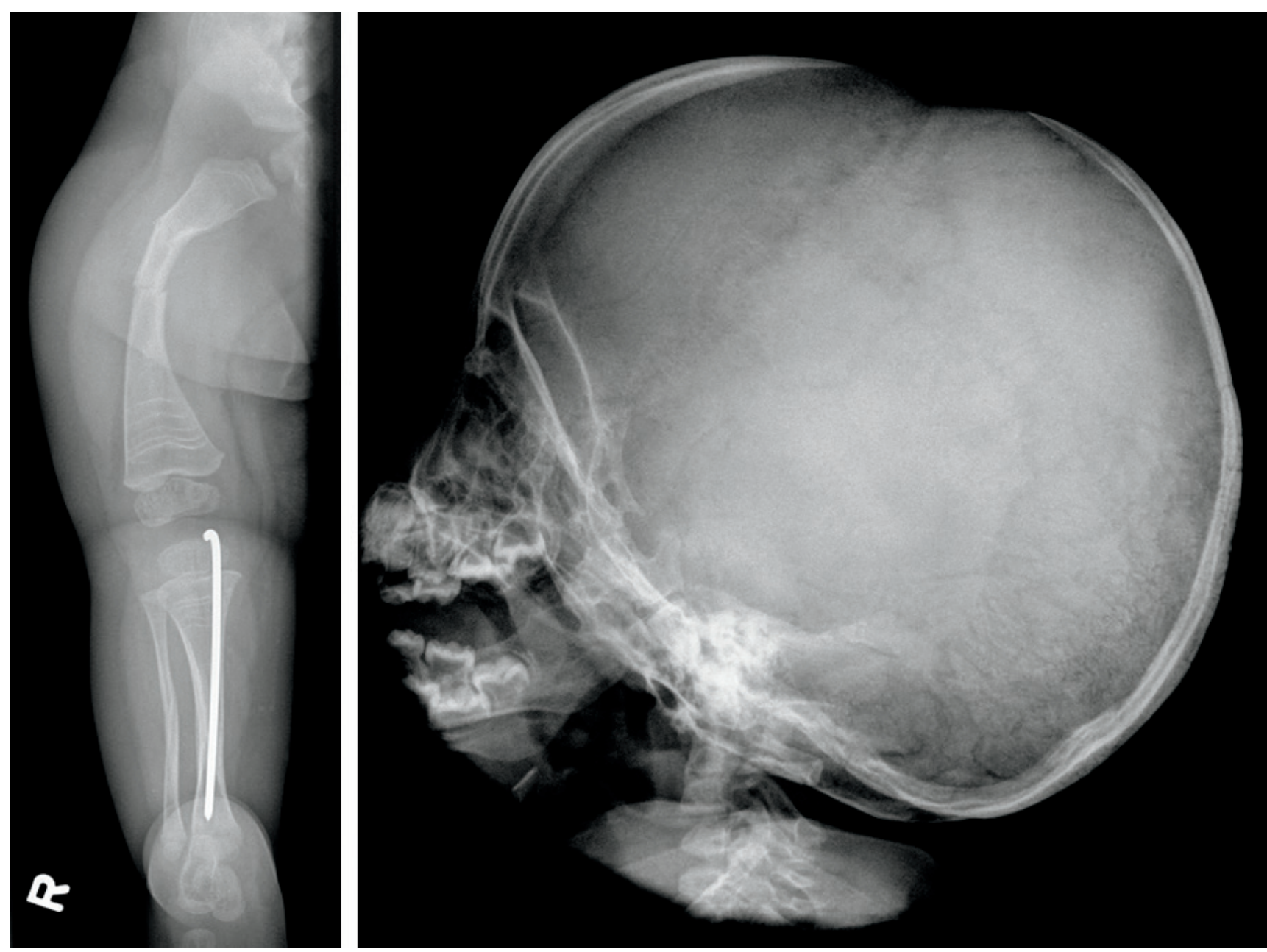

Image 15: 1-year, 8-months-old girl with type III osteogenesis imperfecta. The frontal view of the right lower extremity shows marked demineralization of the visualized bone structures. Marked lateral convexity bowing deformity of the femoral metaphysis is seen with multiple transverse sclerotic bands in the distal femoral and proximal tibial diametaphysis. An acute transverse fracture is visible through the mid femoral diaphysis. Ongoing healing fractures are seen in the mid diaphysis of the right tibia and fibula with the tibial fracture fixated with an intramedullary fixation road. Lateral view of the skull shows multiple wormian bones, especially at the lambdoid sutures. 


\section{Supine}

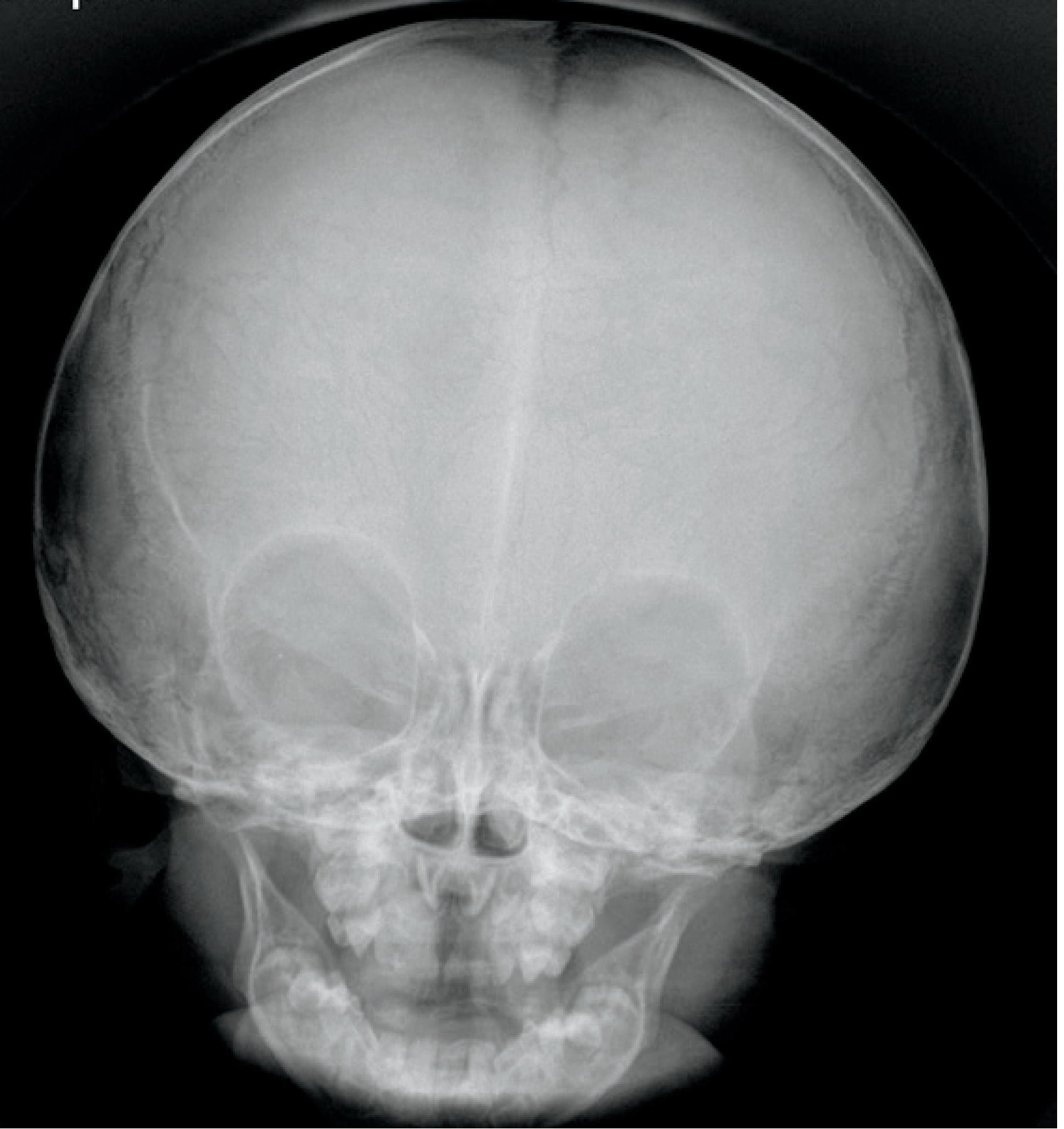

Image 16: Multiple wormian bones.

\section{Page 631}

el Demellawy et al. • Metabolic Bone Disease

ACADEMIC FORENSIC PATHOLOGY: THE OFFICIAL PUBLICATION OF THE NATIONAL ASSOCIATION OF MEDICAL EXAMINERS

C2018 Academic Forensic Pathology International

Downloaded from www.afpjournal.com by an AFP Journal subscriber

This article is for personal use only and may not be shared or distributed in any fashion 


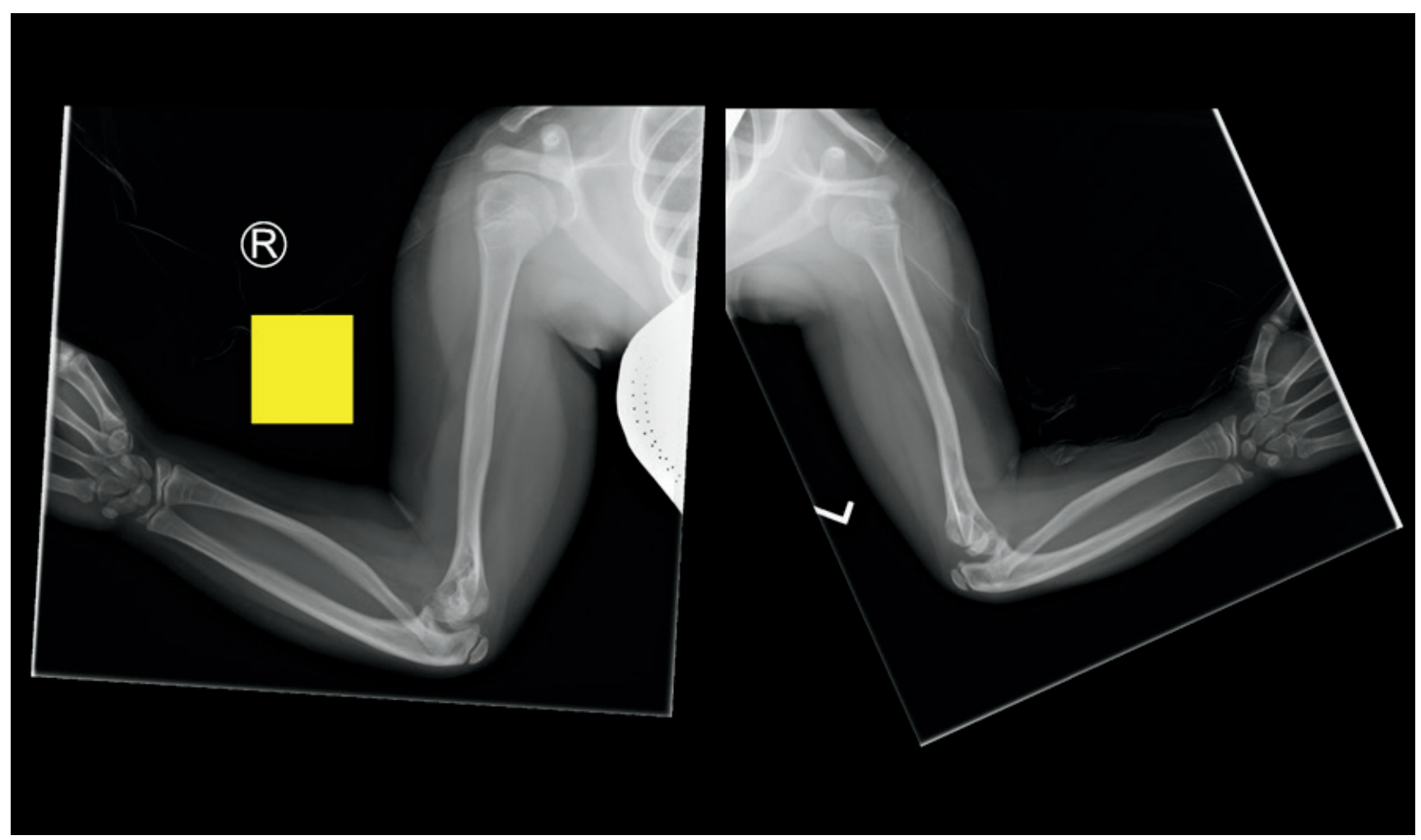

Image 17: Same patient as seen in Image 16 at 11 years of age. Single view of bilateral upper extremities shows mild bowing deformity of bilateral humeral and radial diaphysis with diffuse demineralization and transverse sclerotic bands in bilateral distal radial and ulnar diametaphysis. There is posteroinferior dislocation of bilateral radiocapitelar joints. 


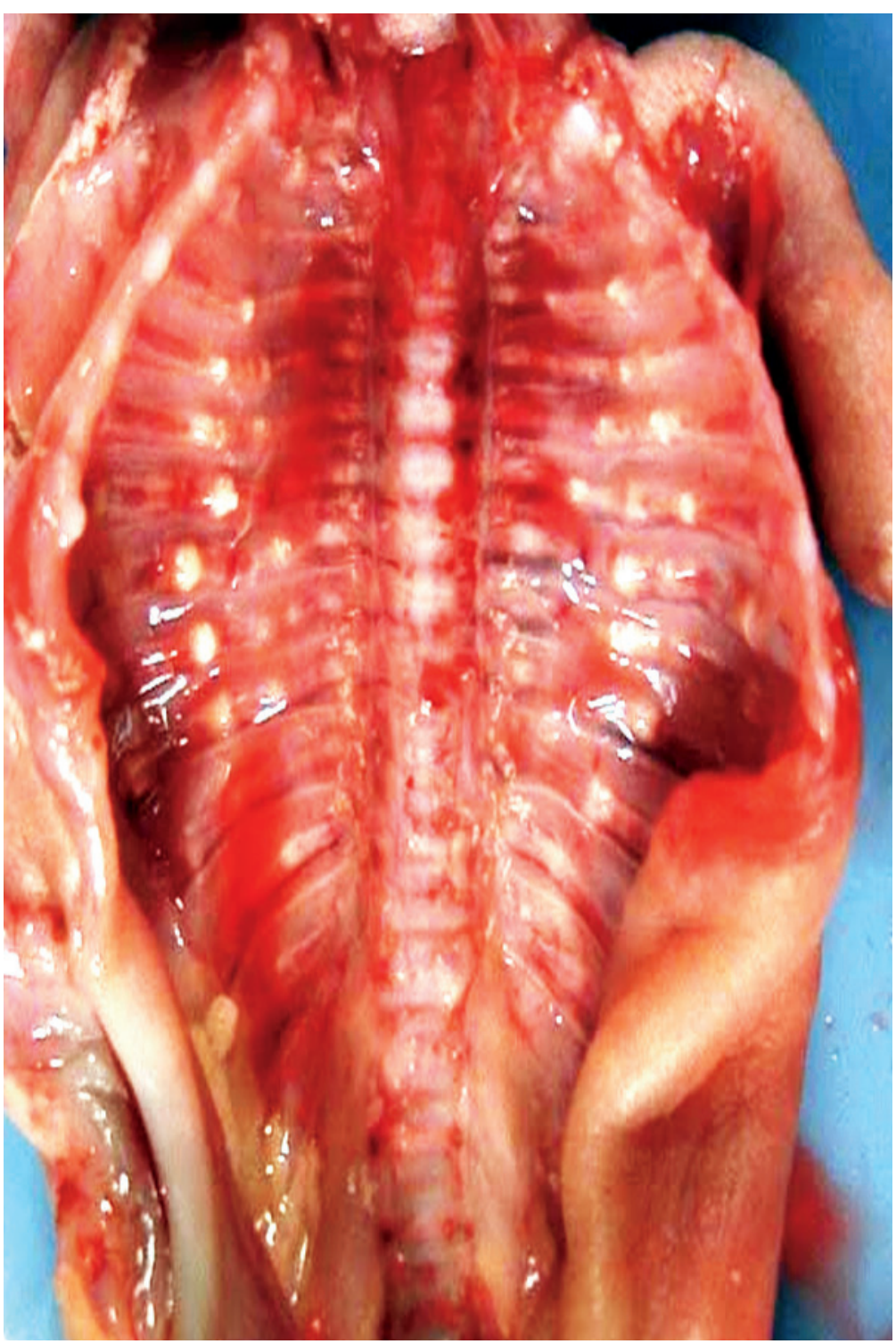

Image 18: Osteogenesis imperfecta gross examination picture of chest cage showing multiple intrauterine fracture calluses.

\section{Page 633}

el Demellawy et al. - Metabolic Bone Disease

ACADEMIC FORENSIC PATHOLOGY: THE OFFICIAL PUBLICATION OF THE NATIONAL ASSOCIATION OF MEDICAL EXAMINERS

C2018 Academic Forensic Pathology International

Downloaded from www.afpjournal.com by an AFP Journal subscriber

This article is for personal use only and may not be shared or distributed in any fashion 


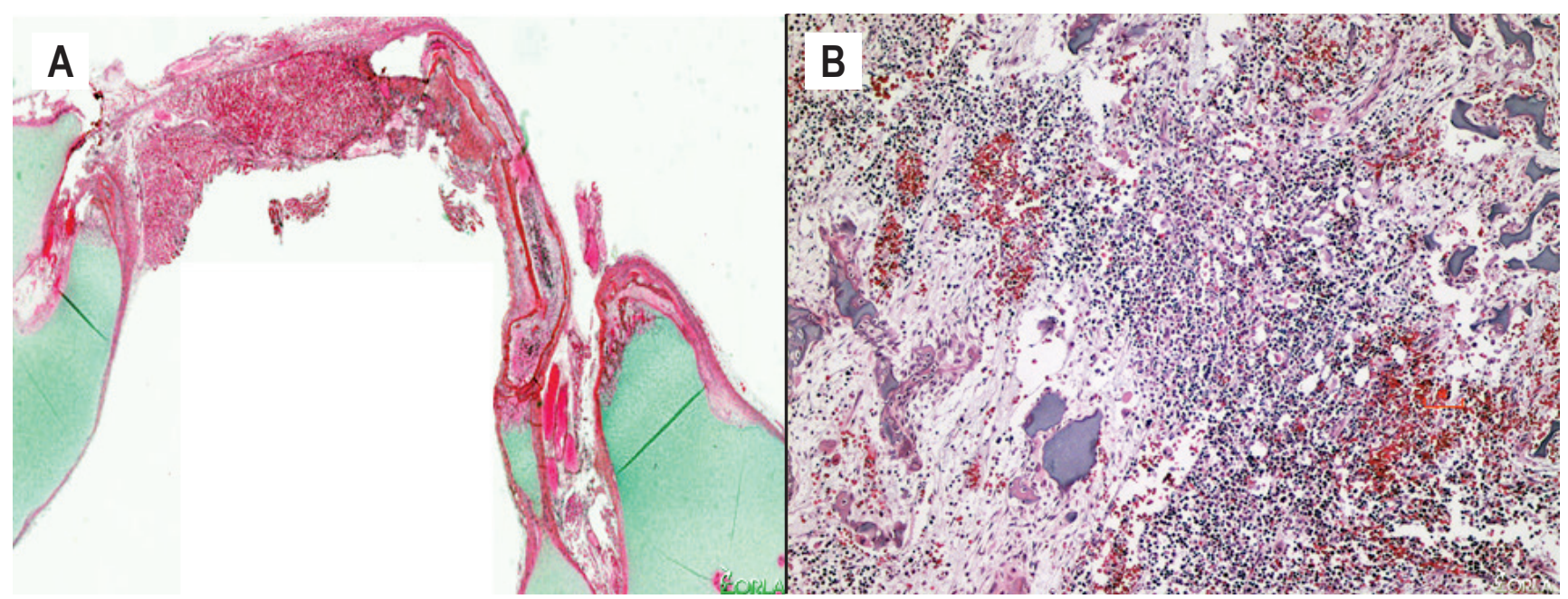

Image 19: Osteogeneses imperfecta bone changes. A) There are angulated and distorted bones that are acquired from recurrent fractures that can start in-utero depending on the osteogenesis imperfect a type (H\&E, x40). B) A severe form of osteogenesis imperfecta with the medullary cavity showing virtually no bony trabeculae but instead thin, sparse and non-connected spicules that are entirely formed of hyaline cartilage (H\&E, x40).

\section{Page 634}

el Demellawy et al. • Metabolic Bone Disease 


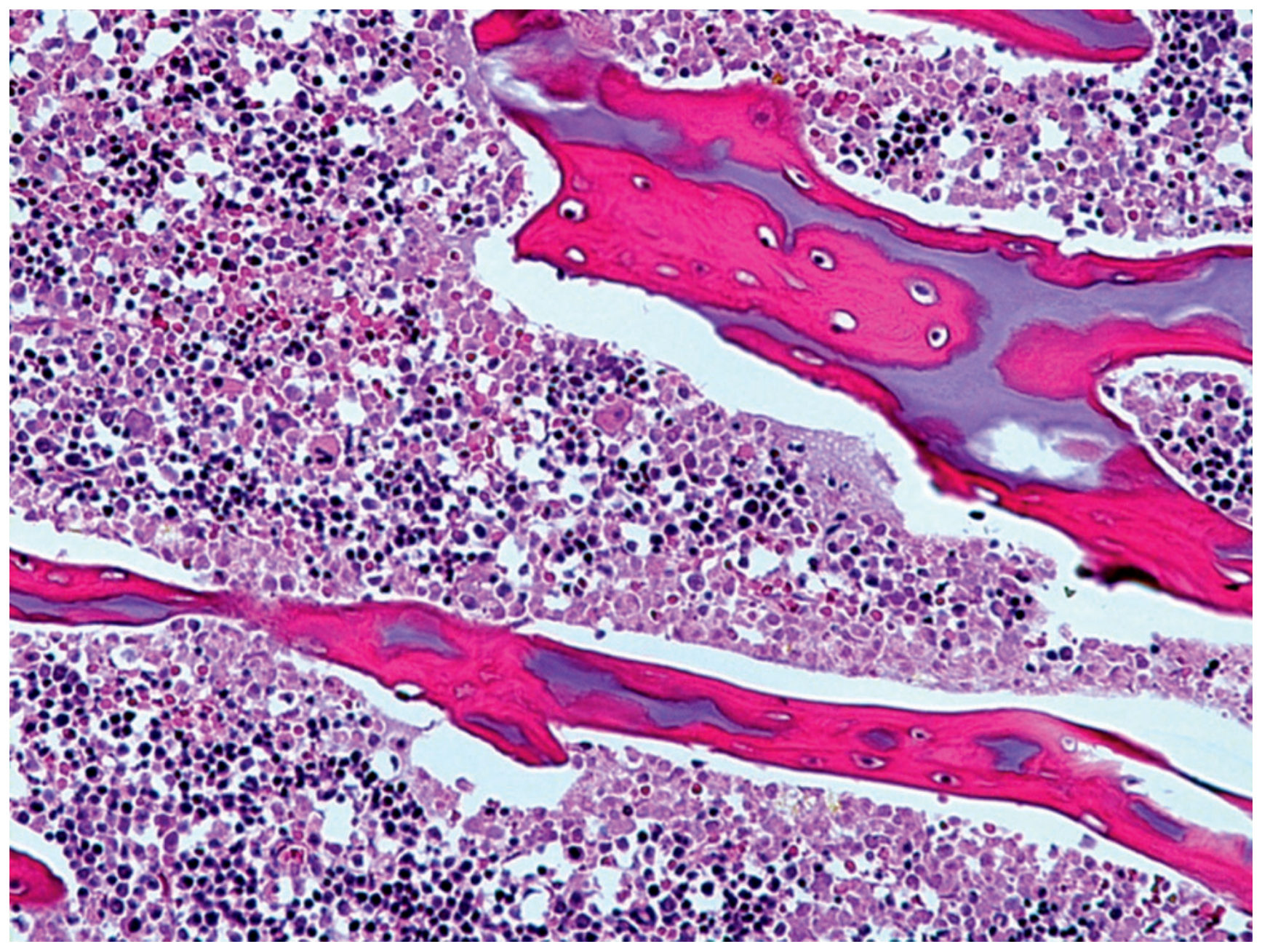

Image 20: Normal medullary bone in a newborn (H\&E, x200). Note the thickness of the boney trabeculae compared to those in osteogenesis imperfecta. Also note the trabeculae to be formed mainly of bone with only a residual central core of hyaline cartilage templates. Compare to osteogenesis imperfecta which is almost entirely formed of hyaline carriage. 


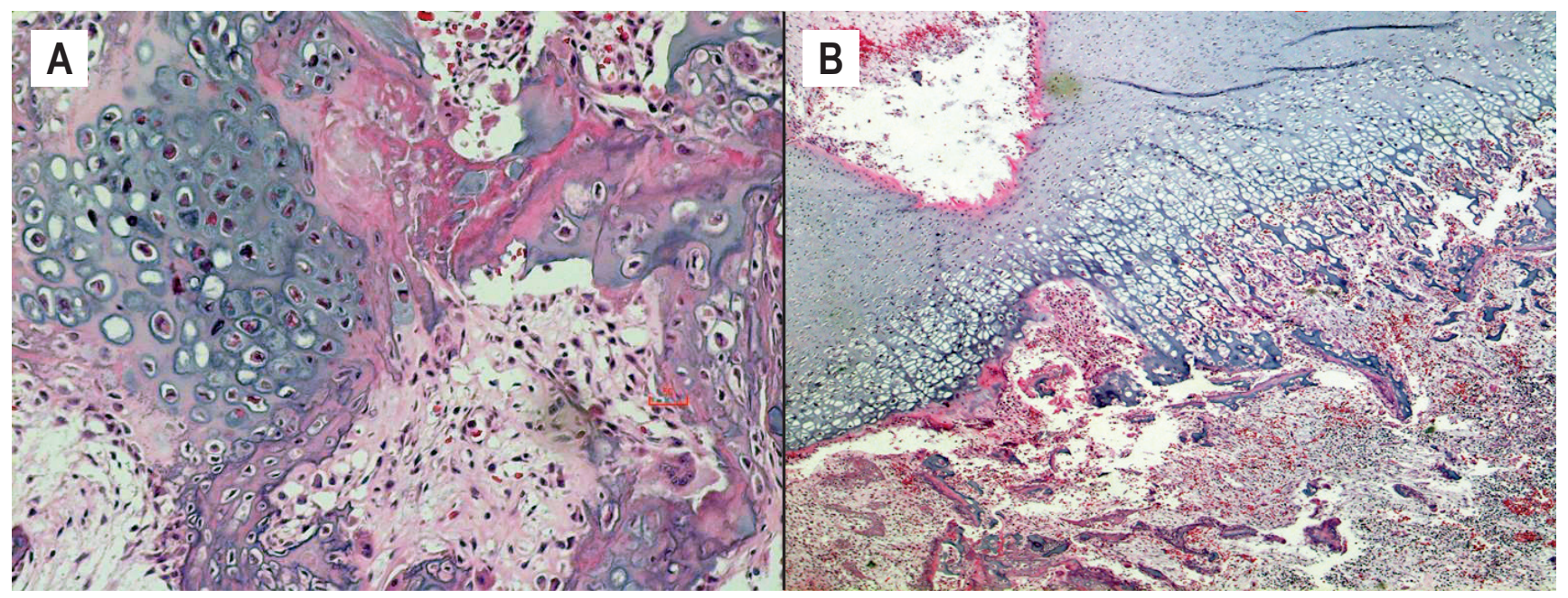

Image 21: Osteogeneses imperfecta bone changes. A) A metadiphyseal subcortical microfrature with abundant cartilaginous fracture callus. Note thin disorganized surrounding bony spicules $(\mathrm{H \& E}, \mathrm{x} 40)$. B) Abnormal growth plate with failure of formation of primary spongiosa with persistence of calcified cartilaginous bars in diaphysis type (H\&E, x40). 


\section{Table 2: Comparison of the Histological Features of Rickets vs Osteogenesis Imperfecta}

\section{Rickets}

Osteogenesis Imperfecta

1. Growth Plate

I. Failure of endochondral ossification and retained cartilaginous cores, I. The epiphyseal growth zone shows a normal organization of the with increased osteoid seams

II. The growth plate is thick, wide, disorganized, and irregular with a poorly defined growth plate, particularly on the metaphyseal side

II. Normal growth plate with unremarkable resting cartilage

III. Tongues of uncalcified cartilage that may extend into metaphysis

III. Occasionally observe a disturbed growth zone due to fractures close to the growth zone and the formation of metaplastic cartilage in this fractured area

IV. Presence of hypertrophic cartilage cells

IV. Normal sparse vascular channels surrounded by loose connective tissue away from spongiosa zone

V. Calcification of the hypertrophic cartilage is reduced or diminished depending on disease severity

V. The primary and secondary spongiosa consist of osteoid with hyper cellular and thin bony trabeculae

VI. Little vascular invasion of this cartilage but in hypophosphaturic rickets there is normal invasion by metaphyseal blood vessels.

VI. At the base of the cartilage, normal longitudinal arrangement is preserved

VII. Zone of proliferation is widened in hypocalcemic rickets but norma in hypophosphaturic rickets

VIII. Unmineralized osteoid seams extending into the primary spongiosa

\section{Trabecular Bone}

Wide osteoid seams

Boney trabeculae in severe forms lack an organized trabecular pattern. Crowded osteocytes within boney trabeculae. Broad large areas of woven bone. In less severe forms still have crowded osteocytes with thin lamellar bone

3. Fractures Callus

Can be present, usually isolated

Usually present and usually multiple at different ages of healing with ample metaplastic cartilage

\section{Medullary Cavity}

Can be replaced by fibrous tissue, and osteoclasts are abundant

Often fibrotic

5. Other

At the base of the cartilage, few calcified bone trabeculae are present, with a loss of the normal longitudinal arrangement

Periosteal lamella can be present in the most severely affected patients with osteogenesis imperfecta type II, especially immediately below the cartilage growth plate and usually associated with a fracture

\section{Page 637}

el Demellawy et al. - Metabolic Bone Disease 


\section{REFERENCES}

1) Glorieux FH, Karsenty G, Thakker RV. Metabolic bone disease and clinically related disorders. 3rd ed. San Diego: Academic Press; c1998. Chapter 26, Metabolic bone disease in children; p. 759-84.

2) Marini JC, Blissett AR. New genes in bone development: what's new in osteogenesis imperfecta. J Clin Endocrinol Metab. 2013 Aug; 98(8):3095-103. PMID: 23771926. PMCID: PMC3733862. https://doi.org/10.1210/jc.2013-1505.

3) Forlino A, Cabral WA, Barnes AM, Marini JC. New perspectives on osteogenesis imperfecta. Nat Rev Endocrinol. 2011 Jun 14; 7(9):54057. PMID: 21670757 . PMCID: PMC3443407. https://doi.org/10.1038/nrendo.2011.81.

4) Kronenberg HM. Developmental regulation of the growth plate. Nature. 2003 May 15; 423(6937):332-6. PMID: 12748651. https://doi.org/10.1038/nature01657.

5) Malcolm A. J. Metabolic bone disease. Curr Diagn Pathol. 2002 Feb; 8(1); 19-25. https://doi.org/10.1054/cdip.2001.0091.

6) Beyens G, Van Hul W. Pathophysiology and genetics of metabolic bone disorders characterized by increased bone turnover. Crit Rev Eukaryot Gene Expr. 2007; 17(3):215-40. PMID: 17725490 https://doi.org/10.1615/critreveukargeneexpr.v17.i3.40.

7) Jilka RL. Biology of the basic multicellular unit and the pathophysiology of osteoporosis. Med Pediatr Oncol. 2003 Sep; 41(3):182-5 PMID: 12858116. https://doi.org/10.1002/mpo.10334.

8) Parfitt AM. Targeted and nontargeted bone remodeling: relationship to basic multicellular unit origination and progression. Bone. 2002 Jan; 30(1):5-7. PMID: 11792557. https://doi.org/10.1016/s8756-3282(01)00642-1.

9) Dominici M, Pritchard C, Garlits JE, et al. Hematopoietic cells and osteoblasts are derived from a common marrow progenitor after bone marrow transplantation. Proc Natl Acad Sci U S A. 2004 Aug 10; 101(32):11761-6. PMID: 15282377. PMCID: PMC511049. https://doi.org/10.1073/pnas.0404626101.

10) Noble BS, Reeve J. Osteocyte function, osteocyte death and bone fracture resistance. Mol Cell Endocrinol. 2000 Jan 25; 159(1-2):7-13. PMID: 10687847. https://doi.org/10.1016/s0303-7207(99)00174-4.

11) Frost HM. Bone remodeling dynamics. Springfield (IL): Charles C. Thomas; $1963.175 \mathrm{p}$.

12) Marotti G, Cane V, Palazzini S, Paulmbo C. Structure-function relationships in the osteocyte. Ital J Min Electrol Metabol. 1990; 4(2): 93-106.

13) Hofbauer LC, Khosla S, Dunstan CR, et al. The roles of osteoprotegerin and osteoprotegerin ligand in the paracrine regulation of bone resorption. J Bone Miner Res. 2000 Jan; 15(1):2-12. PMID: 10646108. https://doi.org/10.1359/jbmr.2000.15.1.2.

14) Roodman GD. Regulation of osteoclast differentiation. Ann N Y Acad Sci. 2006 Apr; 1068:100-9. https://doi.org/10.1196/annals.1346.013.

15) Allgrove J. Classification of disorders of bone and calcium metabolism. Endocr Dev. 2015; 28:291-318. PMID: 26138849. https://doi.org/10.1159/000381570.

16) Allgrove J. Physiology of calcium, phosphate, magnesium and vitamin D. Endocr Dev. 2015; 28:7-32. PMID: 26138833. https://doi.org/10.1159/000380990.

17) Allgrove J. Metabolic bone disease. Paediatr Child Health. 2011; 21(4);187-193 https://doi.org/10.1016/j.paed.2010.09.003.

18) McCarthy, EF. The histology of metabolic bone disease. Diagn Histopathol. 2016; 22(10):378-383. https://doi.org/10.1016/j.mpdhp.2016.09.004.
19) Singer FR, Roodman GD. Paget's disease of bone. In: Bilezikian JP, Raisz LG, Rodan GA, editors. Principles of bone biology. NewYork: Academic Press; 1996. p. 969-78.

20) Compston JE, Croucher PI. Histomorphometric analysis of trabecular bone remodeling in osteoporosis. Bone Miner. 1991 Aug; 14(2): 91-102. PMID: 1912765. https://doi.org/10.1016/0169-6009(91)90086-f.

21) Parafitt AM, Drezner MK, Glorieux FH, et al. Bone histomorphometry: standardization of nomenclature, symbols, and units. Report of the ASBMR Histomorphometry Nomenclature Committee. J Bone Miner Res. 1987 Dec; 2(6):595-610. PMID: 3455637. https://doi.org/10.1002/jbmr.5650020617.

22) Fallon MD, Teitelbaum SL. The interpretation of fluorescent tetracycline markers in the diagnosis of metabolic bone disease. Hum Pathol. 1982 May; 13(5):416-7. PMID: 7076223. https://doi.org/10.1016/s0046-8177(82)80023-3.

23) Kulak CA, Dempster DW. Bone histomorphometry: a concise review for endocrinologists and clinicians. Arq Bras Endocrinol Metabol. 2010 Mar; 54(2):87-98. PMID: 20485895. https://doi.org/10.1590/s0004-27302010000200002.

24) Malluche HH, Sherman D, Meyer W, Massry SG. A new semiautomatic method for quantitative static and dynamic bone histology. Calcif Tissue Int. 1982 Sep; 34(5):439-48. PMID: 6817891. https://doi.org/10.1007/bf02411282.

25) Thorogood P. The developmental specification of vertebrate skull. Development. 1988; 103 Suppl:141-53. PMID: 3074906.

26) Noden DM. Interactions and fates of avian craniofacial mesenchyme. Development. 1988; 103 Suppl:121-40. PMID: 3074905.

27) Couly GF, Coltey PM, Le Douarin NM. The triple origin of the skull in higher vertebrates: a study in quail-chick chimeras. Development. 1993 Feb; 117(2):409-29. PMID: 8330517.

28) Hall BK, Miyake T. The membranous skeleton: the role of cell condensations in vertebrate skeletogenesis. Anat Embryol (Berl). 1992 Jul; 186(2):107-24. PMID: 1510240. https://doi.org/10.1007/bf00174948.

29) Glorieux FH. Rickets, the continuing challenge. N Engl J Med. 1991 Dec 26; 325(26):1875-7. https://doi.org/10.1056/nejm199112263252609.

30) Jagtap VS, Sarathi V, Lila AR, et al. Hypophosphatemic rickets. Indian J Endocrinol Metab. 2012 Mar; 16(2):177-82. PMID: 22470852. PMCID: PMC3313733. https://doi.org/10.4103/2230-8210.

31) Tiosano D, Hochberg Z. Hypophosphatemia: the common denominator of all rickets. J Bone Miner Metab. 2009; 27(4):392-401. PMID: 19504043. https://doi.org/10.1007/s00774-009-0079-1.

32) Sabbagh Y, Carpenter TO, Demay MB. Hypophosphatemia leads to rickets by impairing caspase-mediated apoptosis of hypertrophic chondrocytes. Proc Natl Acad Sci U S A. 2005 Jul 5; 102(27):963742. PMID: 15975027. PMCID: PMC1172249. https://doi.org/10.1073/pnas.0502249102.

33) Cannell JJ, Holick MF. Multiple unexplained fractures in infants and child physical abuse. J Steroid Biochem Mol Biol. 2018 Jan; 175:1822. PMID: 27641737. https://doi.org/10.1016/j.jsbmb.2016.09.012.

34) Ayoub DM, Hyman C, Cohen M, Miller M. A critical review of the classic metaphyseal lesion: traumatic or metabolic? AJR Am J Roentgenol. 2014 Jan; 202(1):185-96. PMID: 24370143. https://doi.org/10.2214/ajr.13.10540.

35) Oppenheimer SJ, Snodgrass GJ. Neonatal rickets. Histopathology and quantitative bone changes. Arch Dis Child. 1980 Dec; 55(12) 945-9. PMID: 7458393. PMCID: PMC1627209. https://doi.org/10.1136/adc.55.12.945.

\section{Page 638}

el Demellawy et al. - Metabolic Bone Disease

ACADEMIC FORENSIC PATHOLOGY: THE OFFICIAL PUBLICATION OF THE NATIONAL ASSOCIATION OF MEDICAL EXAMINERS

O2018 Academic Forensic Pathology International

Downloaded from www.afpjournal.com by an AFP Journal subscriber

This article is for personal use only and may not be shared or distributed in any fashion 
36) Walker A, Kepron C, Milroy CM. Are there hallmarks of child abuse? I. Osseous injuries. Acad Forensic Pathol. 2016 Dec; 6(4):568-90. https://doi.org/10.23907/2016.056.

37) Flaherty EG, Perez-Rossello JM, Levine MA, et al. Evaluating children with fractures for child physical abuse. Pediatrics. 2014 Feb; 133(2):e477-89.

38) Kleinman PK, Perez-Rossello JM, Newton AW, et al. Prevalence of the classic metaphyseal lesion in infants at low versus high risk for abuse. AJR Am J Roentgenol. 2011 Oct; 197(4):1005-8. PMID: 21940592. https://doi.org/10.2214/ajr.11.6540.

39) Perez-Rossello JM, McDonald AG, Rosenberg AE, et al. Absence of rickets in infants with fatal abusive head trauma and classic metaphyseal lesions. Radiology. 2015 Jun; 275(3):810-21. PMID: 25688889. https://doi.org/10.1148/radiol.15141784.

40) Ayoub D, Hyman C, Miller M. Metabolic bone disease in young infants with multiple unexplained fractures: multifactorial in etiology and often confused for child abuse. Poster session presented at: Gordon Research Conference on Biomineralization; 2010 Aug 15-20; Colby-Sawyer College, New London, NH.

41) Tsai A, McDonald AG, Rosenberg AE, et al. High-resolution CT with histopathologic correlates of the classic metaphyseal lesion of infant abuse. Pediatr Radiol. 2014 Feb; 44(2):124-40. PMID: 24481795. https://doi.org/10.1007/s00247-013-2813-z.

42) Miller M, Mirkin LD. Classical metaphyseal lesions thought to be pathognomonic of child abuse are often artifacts or indicative of metabolic bone disease. Med Hypotheses. 2018 Jun; 115:65-71. PMID: 29585201. https://doi.org/10.1016/j.mehy.2018.03.017.

43) Kleinman PK, Perez-Rossello JM, Newton AW, et al. Prevalence of the classic metaphyseal lesion in infants at low versus high risk for abuse. AJR Am J Roentgenol. 2011 Oct; 197(4):1005-8. PMID: 21940592. https://doi.org/10.2214/ajr.11.6540.

44) Cohen MC, Offiah A, Sprigg A, Al-Adnani M. Vitamin D deficiency and sudden unexpected death in infancy and childhood: a cohort study. Pediatr Dev Pathol. 2013 Jul-Aug; 16(4):292-300. PMID: 23600989. https://doi.org/10.2350/13-01-1293-oa.1.

45) Crankson SJ, Fischer JD, Al-Rabeeah AA, Al-Jaddan SA. Pediatric thoracic trauma. Saudi Med J. 2001 Feb; 22(2):117-20. PMID: 11299403.

46) Garcia VF, Gotschall CS, Eichelberger MR, Bowman LM. Rib fractures in children: a marker of severe trauma, J Trauma. 1990 Jun; 30(6):695-700. PMID: 2352299 https://doi.org/10.1097/00005373-199006000-00007.

47) Miller ME, Hangartner TN. Temporary brittle bone disease: association with decreased fetal movement and osteopenia. Calcif Tissue Int. 1999 Feb; 64(2):137-43. PMID: 9914321. https://doi.org/10.1007/s002239900592.

48) Miller ME, Ayoub D, Hyman C. Metabolic bone disease in young infants with multiple unexplained fractures: multifactorial in etiology and often confused for child abuse. Poster session presented at: Pediatric Academic Society Meetings; 2011 Apr 30-May 3; Denver, CO.

49) Miller M, Ward T, Stolfi A, Ayoub D. Overrepresentation of multiple birth pregnancies in young infants with four metabolic bone disorders: further evidence that fetal bone loading is a critical determinant of fetal and young infant bone strength. Osteoporos Int. 2014 Jul; 25(7):1861-73. PMID: 24696017. https://doi.org/10.1007/s00198-014-2690-9.

50) Yokoyama K, Takahashi N, Yada Y, et al. Prolonged maternal magnesium administration and bone metabolism in neonates. Early Hum Dev. 2010 Mar; 86(3):187-91. PMID: 20226604.

https://doi.org/10.1016/j.earlhumdev.2010.02.007.
51) Wedig KE, Kogan J, Schorry EK, Whitsett JA. Skeletal demineralization and fractures caused by fetal magnesium toxicity. J Perinatol. 2006 Jun; 26(6):371-4. PMID: 16724078. https://doi.org/10.1038/sj.jp.7211508.

52) Malaeb SN, Rassi A, Haddad MC, et al. Bone mineralization in newborns whose mothers received magnesium sulphate for tocolysis of premature labor. Pediatr Radiol. 2004 May; 34(5):384-6. PMID: 14985884. https://doi.org/10.1007/s00247-004-1148-1

53) Kaplan W, Haymond MW, McKay S, Karaviti LP. Osteopenic effects of $\mathrm{MgSO} 4$ in multiple pregnancies. $J$ Pediatr Endocrinol Metab. 2006 Oct; 19(10):1225-30. PMID: 17172083. https://doi.org/10.1515/jpem.2006.19.10.1225.

54) Nassar AH, Sakhel K, Maarouf H, et al. Adverse maternal and neonatal outcome of prolonged course of magnesium sulfate tocolysis Acta Obstet Gynecol Scand.2006; 85(9):1099-103. PMID: 16929415. https://doi.org/10.1080/00016340600756896.

55) Matsuda $Y$, Maeda $Y$, Ito $M$, et al. Effect of magnesium sulfate treatment on neonatal bone abnormalities. Gynecol Obstet Invest. 1997; 44(2):82-8. PMID: 9286718 https://doi.org/10.1159/000291492.

56) Forlino A, Marini JC. Osteogenesis imperfecta. Lancet. 2016 Apr 16; 387(10028):1657-71. PMID: 26542481. https://doi.org/10.1016/s0140-6736(15)00728-x.

57) Folketstad L, Hald JD, Ersbøll AK, et al. Fracture rates and fracture sites in patients with osteogenesis imperfecta: a nationwide register-based cohort study. J Bone Miner Res. 2017 Jan; 32(1):125-134. PMID: 27448250. https://doi.org/10.1002/jbmr.2920.

58) Marini JC. Nelson textbook of pediatrics. 19th ed. Philadelphia: Elsevier Health Sciences; c2011. Chapter 692, Osteogenesis imperfecta; p. 2437-40.

59) Marini JC, Reich A, Smith SM. Osteogenesis imperfecta due to mutations in non-collagenous genes: lessons in the biology of bone formation. Curr Opin Pediatr. 2014 Aug; 26(4):500-7. PMID: 25007323. PMCID: PMC4183132.

60) Barnes AM, Chang W, Morello R, et al. Deficiency of cartilageassociated protein in recessive lethal osteogenesis imperfecta. $N$ Engl J Med. 2006 Dec 28; 355(26):2757-64. PMID: 17192541. https://doi.org/10.1056/nejmoa063804.

61) Van Dijk FS, Pals G, Van Rijn RR, et al. Classification of osteogenesis imperfecta revisited. Eur J Med Genet. 2010 Jan-Feb; 53(1):1-5. PMID: 19878741. https://doi.org/10.1016/j.ejmg.2009.10.007.

62) Marini JC, Blissett AR. New genes in bone development: what's new in osteogenesis imperfecta. J Clin Endocrinol Metab. 2013 Aug; 98(8):3095-103. PMID: 23771926. PMCID: PMC3733862. https://doi.org/10.1210/jc.2013-1505.

63) Forlino A, Cabral WA, Barnes AM, Marini JC. New perspectives on osteogenesis imperfecta. Nat Rev Endocrinol. 2011 Jun 14; 7(9):54057. PMID: 21670757. PMCID: PMC3443407. https://doi.org/10.1038/nrendo.2011.81.

64) Marini JC, Reich A, Smith SM. Osteogenesis imperfecta due to mutations in non-collagenous genes: lessons in the biology of bone formation. Curr Opin Pediatr. 2014 Aug; 26(4):500-7. https://doi.org/10.1097/mop.0000000000000117.

65) Baron R, Gertner JM, Lang R, Vignery A. Increased bone turnover with decreased bone formation by osteoblasts in children with osteogenesis imperfecta tarda. Pediatr Res. 1983 Mar; 17(3):204-7. PMID: 6835724 https://doi.org/10.1203/00006450-198303000-00007.

\section{Page 639}

el Demellawy et al. - Metabolic Bone Disease

ACADEMIC FORENSIC PATHOLOGY: THE OFFICIAL PUBLICATION OF THE NATIONAL ASSOCIATION OF MEDICAL EXAMINERS

O2018 Academic Forensic Pathology International

Downloaded from www.afpjournal.com by an AFP Journal subscriber

This article is for personal use only and may not be shared or distributed in any fashion 
66) Uveges TE, Collin-Osdoby P, Cabral WA, et al. Cellular mechanism of decreased bone in Brtl mouse model of OI: imbalance of decreased osteoblast function and increased osteoclasts and their precursors. J Bone Miner Res. 2008 Dec; 23(12):1983-94. PMID: 18584089. PMCID: PMC2686922. https://doi.org/10.1359/jbmr.080804.

67) Rauch F, Travers R, Parfitt AM, Glorieux FH. Static and dynamic bone histomorphometry in children with osteogenesis imperfecta. Bone. 2000 Jun; 26(6):581-9. PMID: 10831929. https://doi.org/10.1016/s8756-3282(00)00269-6.

68) Kang H, Aryal ASC, Marini JC. Osteogenesis imperfecta: new genes reveal novel mechanisms in bone dysplasia. Transl Res. 2017 Mar; 181:27-48. PMID: 27914223. https://doi.org/10.1016/j.trs1.2016.11.005.

69) Van Dijk FS, Sillence DO. Osteogenesis imperfecta: clinical diagnosis, nomenclature and severity assessment. Am J Med Genet A. 2014 Jun; 164A(6):1470-81.

PMID: 24715559. PMCID: PMC4314691 https://doi.org/10.1002/ajmg.a.36545.

70) Van Dijk FS, Cobben JM, Kariminejad A, et al. Osteogenesis imperfecta: a review with clinical examples. Mol Syndromol. 2011 Dec; 2(1):1-20. PMID: 22570641. PMCID: PMC3343766. https://doi.org/10.1159/000332228.

71) McAllion SJ, Paterson CR. Causes of death in osteogenesis imperfecta. J Clin Pathol. 1996 Aug; 49(8):627-30. PMID: 8881910. PMCID: PMC500603. https://doi.org/10.1136/jcp.49.8.627.
72) Renaud A, Aucourt J, Weill J, et al. Radiographic features of osteogenesis imperfecta. Insights Imaging. 2013 Aug; 4(4):417-29. PMID: 23685748. PMCID: PMC3731461. https://doi.org/10.1007/s13244-013-0258-4.

73) Greeley $\mathrm{CH}$, Donaruma-Kwoh M, Vettimattam M, et al. Fractures at diagnosis in infants and children with osteogenesis imperfecta. J Pediatr Orthop. 2013 Jan; 33(1):32-6. PMID: 23232376. PMCID: PMC3521163. https://doi.org/10.1097/bpo.0b013e318279c55d.

74) Paterson CR, Burns J, McAllion SJ. Osteogenesis imperfecta: the distinction from child abuse and the recognition of a variant form. Am J Med Genet. 1993 Jan 15; 45(2):187-92. PMID: 8456801. https://doi.org/10.1002/ajmg.1320450208

75) Greeley CS, Donnaruma-Kwoh M. Diagnosis in infants and children with osteogenesis imperfecta. J Pediatr Orthop. 2015 Oct-Nov; 35(7):e82. PMID: 26057070 . PMCID: PMC4613794. https://doi.org/10.1097/bpo.0000000000000564.

76) Zarate YA, Clingenpeel R, Sellars EA, et al. COL1A1 and COL1A2 sequencing results in cohort of patients undergoing evaluation for potential child abuse. Am J Med Genet A. 2016 Jul; 170(7):1858-62. PMID: 27090748. https://doi.org/10.1002/ajmg.a.37664.

77) Pepin MG, Byers PH. What every clinical geneticist should know about testing for osteogenesis imperfecta in suspected child abuse cases. Am J Med Genet C Semin Med Genet. 2015 Dec; 169(4):30713. PMID: 26566591. https://doi.org/10.1002/ajmg.c.31459.

\section{Page 640}

el Demellawy et al. • Metabolic Bone Disease 